\title{
Evidence for Glycine as an Inhibitory Neurotransmitter of Vestibular, Reticular, and Prepositus Hypoglossi Neurons That Project to the Cat Abducens Nucleus
}

\author{
Robert F. Spencer, ${ }^{1}$ Robert J. Wenthold, ${ }^{2}$ and Robert Baker ${ }^{3}$ \\ 'Department of Anatomy, Medical College of Virginia, Richmond, Virginia 23298, 'Laboratory of Neuro-otolaryngology, \\ National Institute of Neurological and Communicative Disorders and Stroke, National Institutes of Health, Bethesda, \\ Maryland 20892, and ${ }^{3}$ Department of Physiology and Biophysics, New York University Medical Center, New York, New \\ York 10016
}

The localization and distribution of brain-stem afferent neurons to the cat abducens nucleus has been examined by high-affinity uptake and retrograde transport of ${ }^{3} \mathrm{H}$-glycine. Injections of ${ }^{3} \mathrm{H}$-glycine selectively labeled (by autoradiography) only neurons located predominantly in the ipsilateral medial vestibular and contralateral prepositus hypoglossi nuclei, and in the contralateral dorsomedial reticular formation, the latter corresponding to the location of inhibitory burst neurons. The specificity of uptake and retrograde transport of ${ }^{3} \mathrm{H}-\mathrm{glycine}$ was indicated by the absence of labeling of the dorsomedial medullary reticular neurons ipsilateral and in close proximity to the injection site, where local uptake by diffusion could have occurred. The selectivity of uptake and transport was demonstrated by the absence of retrograde labeling following injections of ${ }^{3} \mathrm{H}-\mathrm{GABA}$ or ${ }^{3} \mathrm{H}$ leucine into the abducens nucleus.

The immunohistochemical localization of glycine and GABA revealed a differential distribution of the 2 inhibitory neurotransmitter candidates in the extraocular motor nuclei. Glycine-immunoreactive staining of synaptic endings in the abducens nucleus was dense with a widespread soma-dendritic distribution but was sparse in the trochlear and oculomotor nuclei. By contrast, GABA-immunoreactive staining within the oculomotor and trochlear nuclei was associated with synaptic endings that were particularly prominent on the somata of motoneurons. GABA-immunoreactive staining in the abducens nucleus, however, was sparse. These differences between glycine- and GABA-immunoreactive staining in the extraocular motor nuclei were correlated with differences in the immunoreactivity of axons in the descending (glycine) and ascending (GABA) limbs of the medial longitudinal fasciculus. Glycine-immunoreactive neurons, furthermore, were observed in the same locations as neurons

Received Oct. 21, 1988; revised Jan. 17, 1989; accepted Jan. 18, 1989

This work was supported in part by US Public Health Service MERIT Award EY02191, Research Grant EY02007, Program Project Grant NS13742, and Biomedical Research Support Grants RR05430, RR05697, and RR05724. The technical assistance of Barbara Rapisarda, Leslie Hisle, and Lynn Davis is greatly appreciated.

Correspondence should be addressed to Dr. Robert F. Spencer, Department of Anatomy, Medical College of Virginia, P.O. Box 709, MCV Station, Richmond, VA 23298-0709.

Copyright (C) 1989 Society for Neuroscience $0270-6474 / 89 / 082718-19 \$ 02.00 / 0$ that were labeled autoradiographically by retrograde transport of ${ }^{3} \mathrm{H}-\mathrm{glycine}$ from the abducens nucleus.

Electrophysiological recordings from abducens motoneurons and internuclear neurons revealed a marked reduction in the slow positivity of the orthodromic extracellular potential elicited by ipsilateral vestibular nerve stimulation following systemic administration of strychnine, an antagonist of glycine. Intracellular recordings demonstrated that the vestibular-evoked disynaptic inhibitory postsynaptic potentials in abducens neurons were effectively blocked by strychnine but were unaffected by picrotoxin, an antagonist of GABA.

These correlative morphological and physiological findings suggest that glycine may be an inhibitory neurotransmitter of neurons that are related to the horizontal vestibuloocular and saccadic eye movement systems. By contrast, GABA may be the neurotransmitter of second-order inhibitory vestibular neurons that are related to the vertical semicircular canals and that establish synaptic connections with oculomotor and trochlear motoneurons.

Reciprocal excitatory and inhibitory synaptic connections of second-order vestibular neurons with motoneurons in the oculomotor and trochlear nuclei provide the direct physiological basis for the vertical vestibulo-ocular reflex (Highstein, 1971, 1973a; Highstein and Ito, 1971; Highstein et al., 1971; Baker and Precht, 1972; Precht and Baker, 1972; Berthoz et al., 1973; Baker and Berthoz, 1974; Ito et al., 1976a, b; Uchino et al., 1978, 1980). Most, if not all, of the inhibitory vestibular neurons that are related to the anterior and posterior vertical semicircular canals are located in the superior vestibular nucleus (Highstein and Ito, 1971; Yamamoto et al., 1978; Uchino et al., 1981, 1986; Baker et al., 1982; Graf et al., 1983; Mitsacos et al., 1983; Uchino and Suzuki, 1983; Hirai and Uchino, 1984; Graf and Ezure, 1986; Highstein et al., 1987; McCrea et al., 1987a). The axons of these neurons ascend in the ipsilateral medial longitudinal fasciculus (MLF; McMasters et al., 1966; Tarlov, 1970; Gacek, 1971; Carpenter and Cowie, 1985) and establish synaptic connections predominantly on the somata and proximal dendrites of motoneurons in the oculomotor and trochlear nuclei (Bak et al., 1976; Demêmes and Raymond, 1980; Spencer and Baker, 1983). The disynaptic IPSPs elicited in oculomotor and trochlear motoneurons by electrical stimulation of the ipsilateral vestibular nerve are effectively blocked by systemic or iontophoretic administration of bicuculline or picrotoxin (Ito et al., 
1970; Obata and Highstein, 1970; Precht et al., 1973a). Lesions of the superior vestibular nucleus or the MLF furthermore reduce levels of GABA synthesis in the trochlear nucleus (RofflerTarlov and Tarlov, 1975). Collectively, these findings suggest that GABA is the inhibitory neurotransmitter utilized in the vertical vestibulo-ocular reflex.

The horizontal vestibulo-ocular reflex, by contrast, is mediated predominantly by reciprocal excitatory and inhibitory synaptic connections of second-order vestibular neurons with motoneurons and internuclear neurons in the abducens nucleus (Precht et al., 1967; Richter and Precht, 1968; Baker et al., 1969b, 1980; Maeda et al., 1971, 1972; Highstein, 1973b; Baker and Highstein, 1975; Hikosaka et al., 1977; Uchino et al., 1979, 1982; Ishizuka et al., 1980; McCrea et al., 1980). Abducens motoneurons innervate predominantly the ipsilateral lateral rectus muscle (Baker et al., 1969a; Baker and Highstein, 1975; Spencer and Sterling, 1977; Steiger and Büttner-Ennever, 1978; Spencer et al., 1980; Spencer and Porter, 1981; Highstein et al., 1982; Porter et al., 1983; Spencer and Baker, 1986). Internuclear neurons establish monosynaptic excitatory synaptic connections with medial rectus motoneurons in the contralateral oculomotor nucleus (Graybiel and Hartwieg, 1974; Baker and Highstein, 1975; Gacek, 1977; Maciewicz and Spencer, 1977; Spencer and Sterling, 1977; Highstein and Baker, 1978; Steiger and BüttnerEnnever, 1978, 1979; Carpenter and Batton, 1980; Highstein et al., 1982; Carpenter and Carleton, 1983; Spencer and Baker, 1986). In contrast to the vertical canal-related second-order inhibitory vestibular neurons, the inhibitory second-order vestibular neurons that project to the abducens nucleus are located in the rostral portion of the medial vestibular nucleus (Maciewicz et al., 1977; Gacek, 1979; McCrea et al., 1980; Uchino et al., 1981, 1982; Nakao et al., 1982; Carleton and Carpenter, 1983; Uchino and Suzuki, 1983; Langer ct al., 1986; McCrea et al., 1987b; Belknap and McCrea, 1988; Ohgaki et al., 1988). In addition to synaptic terminations in the ipsilateral abducens nucleus, the axons of some of these neurons branch and descend in the MLF toward the spinal cord (McCrea et al., 1980; Isu and Yokota, 1983; Ohgaki et al., 1988). Systemic injection of bicuculline or picrotoxin causes depression of the antidromic field potential and the slow positivity that normally accompanies the disynaptic IPSP elicited in abducens motoneurons by ipsilateral vestibular nerve stimulation (Highstein, 1973b). Similar administration of strychnine, however, effectively abolishes the disynaptic vestibular IPSP in neck motoneurons in the cervical spinal cord, suggesting that glycine is the inhibitory neurotransmitter utilized in this descending vestibulo-collic pathway (Felpel, 1972). Both GABA and glycine furthermore have been implicated in vestibular commissural inhibition (Precht et al., 1973b).

One approach toward identifying the potential neurotransmitter utilized by afferent neurons is retrograde autoradiographic labeling with radioactive transmitter substances (Cuénod et al., 1982). The basis of this approach is that neurons utilizing a specific neurotransmitter possess a high-affinity uptake mechanism for that transmitter (Hökfelt and Ljungdahl, 1975). In the present study, injections of ${ }^{3} \mathrm{I}$-glycine into the cat abducens nucleus have selectively labeled (by retrograde transport) neurons located in the medial vestibular and prepositus hypoglossi nuclei and in the contralateral dorsomedial medullary reticular formation. These findings have been corroborated by the immunohistochemical localization of glycine and GABA in the oculomotor, trochlear, and abducens nuclei and by the phar- macological antagonism of the vestibular-evoked inhibition in abducens neurons demonstrated electrophysiologically by extraand intracellular recordings.

\section{Materials and Methods}

Experimental animals. Morphological experiments were performed on 31 adult cats, $2.1-3.2 \mathrm{~kg}$, under sodium pentobarbital anesthesia (40 $\mathrm{mg} / \mathrm{kg}$ ) administered intraperitoneally. Animals remained sedated during the postinjection survival periods by supplemental doses of the anesthetic. At the completion of each experiment, animals were euthanized by a lethal dose of sodium pentobarbital followed by transcardial perfusion of a fixative solution, as described in each section below. Fixative was preceded by a vascular wash with physiological saline. Heparin sodium (2000 IU) and sodium nitrite (10 mg) were administered $30 \mathrm{~min}$ and $30 \mathrm{sec}$, respectively, prior to the perfusion via a catheter in a femoral vein.

Retrograde autoradiographic labeling. In 15 cats, the lateral rectus muscles were injected bilaterally with $15-25 \mu \mathrm{l}$ of $10 \% \mathrm{HRP}$ (BoehringerMannheim) in $0.9 \%$ saline, as previously described (Spencer and Sterling, 1977; Spencer et al., 1980), to provide a reference delineation of the neuronal boundary of the abducens nucleus. Twenty-four hours later, the posterior vermis of the cerebellum was aspirated to expose the floor of the IVth ventricle. Calibrated glass micropipettes containing $\left[2-{ }^{3} \mathrm{H}\right]$ glycine $(18 \mathrm{Ci} / \mathrm{mmol}$; Amersham TRK.71), 4-amino- $n-[2,3-$ $\left.{ }^{3} \mathrm{H}\right]$ butyric acid (GABA; $78 \mathrm{Ci} / \mathrm{mmol}$; Amersham TRK. 527), or L-[4,5$\left.{ }^{3} \mathrm{H}\right]$ leucine $(178 \mathrm{Ci} / \mathrm{mmol}$; Amersham TRK.510) were mounted in a holder attached to a Kopf manipulator, and the tip was lowered into the abducens nucleus using the facial colliculus as a landmark. Tritiated amino acids were prepared by evaporation of the stock solutions under nitrogen atmosphere and reconstitution in sterile $0.9 \%$ saline to a concentration of $50-100 \mu \mathrm{Ci} / \mathrm{ml}$. Injections of $0.2-0.5 \mu \mathrm{l}$ were made by positive pressure (10-20 psi) applied through the tip of the micropipette (Mize et al., 1981). Aminooxyacetic acid $(40 \mathrm{mg} / \mathrm{kg}$ ) was administered intraperitoneally to animals that were injected with ${ }^{3} \mathrm{H}-\mathrm{GABA}$ to inhibit the metabolism of GABA by GABA-transaminase.

After postinjection survival periods of $2-12 \mathrm{hr}(\mathrm{GABA})$ or $12-18 \mathrm{hr}$ (glycine, leucine), animals were killed by transcardial perfusion of fixative solution containing $1.0 \%$ paraformaldehyde and $1.25 \%$ glutaraldehyde in $0.1 \mathrm{~m}$ phosphate buffer with $0.002 \%$ calcium chloride, $\mathrm{pH}$ 7.2. The brain stem was blocked in the stereotaxic coronal plane, and serial $25 \mu \mathrm{m}$ sections were cut with a Vibratome and collected in $0.1 \mathrm{M}$ phosphate buffer, $\mathrm{pH}$ 7.2. Sections were processed for the histochemical localization of HRP using 3,3'-diaminobenzidine tetrahydrochloride as the chromogen (Spencer and Sterling, 1977). Two series of alternating sections were placed on microscope slides pretreated with chrom alumgelatin, defatted, and hydrated. Slides were coated with Kodak NTB-2 nuclear track emulsion diluted 1:1 with distilled water. After exposures of 2-6 weeks at $4^{\circ} \mathrm{C}$, slides were developed in Kodak D-19 developer for $2 \mathrm{~min}$ at $17^{\circ} \mathrm{C}$ and fixed for $6 \mathrm{~min}$ in Kodak Ektaflo fixer. Sections were counterstained in $0.25 \%$ thionin, dehydrated, and mounted with Permount. Sections were examined and photographed by light microscopy using bright-field illumination. The locations of retrogradely labeled neurons were charted using a microcomputer-controlled digitizer (Minnesota Datametrics) connected to $X$ - and $Y$-axis encoders attached to the stage of the microscope.

Retrograde HRP labeling. To provide a comparison for the locations of autoradiographically labeled neurons, injections of $25 \% \mathrm{HRP}$ (Boeh-

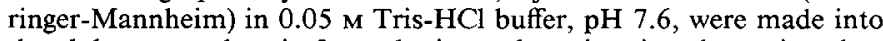
the abducens nucleus in 8 cats by iontophoresis using glass microelectrodes with $2 \mu \mathrm{A}$ positive pulses of $250 \mathrm{msec}$ duration delivered at 2 IIz for $20-30 \mathrm{~min}$. The floor of the IVth ventricle was exposed by aspiration of the posterior vermis of the cerebellum, and the location of the abducens nucleus was determined physiologically by recording antidromic field potentials elicited by electrical stimulation of the VIth nerve in the orbit. After 18-24 hr, animals were killed by transcardial perfusion of fixative solution as described above. The brain stem was blocked in the stereotaxic coronal plane, and $50 \mu \mathrm{m}$ sections were cut with a Vibratome and collected serially in $0.1 \mathrm{M}$ phosphate buffer. Sections were processed for the histochemical localization of HRP using tetramethylbenzidine dihydrochloride (TMB) as the chromogen (Mesulam, 1978). Following the reaction with hydrogen peroxide, sections were washed in acetate buffer, placed on pretreated microscope slides, counterstained with neutral red, dehydrated, and mounted with Permount. Sections were examined and photographed by light microscopy 
using bright- and dark-field illumination. The locations of retrogradely labeled neurons were charted as described above.

Glycine and $G A B A$ immunohistochemistry. Eight cats were perfused with fixative solution containing $4.0 \%$ paraformaldehyde and $0.1 \%$ glutaraldehyde (TAAB) in $0.1 \mathrm{M}$ phosphate buffer with $0.002 \%$ calcium chloride, $\mathrm{pH} 7.2$. Vibratome sections $(50 \mu \mathrm{m})$ through the brain stem

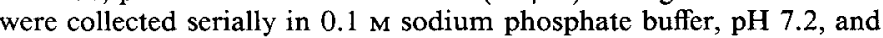
were divided into 3 groups. Two groups of sections were processed for the immunohistochemical localization of glycine or GABA using antibodies generated in rabbit against glycine or GABA conjugated to BSA with glutaraldehyde. The production characterization, and specificity of these antibodies are described elsewhere (Wenthold et al., 1986, 1987). Sections were immersed for $1 \mathrm{hr}$ in 10\% normal goat serum (NGS) and $1 \% \mathrm{BSA}$ in $0.01 \mathrm{M}$ PBS containing $0.1 \%$ Triton $\mathrm{X}-100$ and $0.1 \mathrm{M}$ lysine, and then incubated in primary antibody (1:1500 for GABA, 1:750 for glycine) containing $1 \%$ NGS and $1 \%$ BSA with $0.1 \%$ Triton $\mathrm{X}-100$ in PBS for $18-24$ hr at $4^{\circ} \mathrm{C}$ with constant agitation. As a control, some sections were incubated in the same solution without the addition of primary antibody. After incubation, sections were washed for $30 \mathrm{~min}$ in 3 changes of PBS and immersed in biotinylated anti-rabbit $\operatorname{IgG}$ (Vector) in PBS with 1\% NGS for $60 \mathrm{~min}$ at room temperature with constant agitation. Following the secondary antibody incubation, sections were washed in PBS and immersed in an avidin : biotin-HRP complex (Vector) for $60 \mathrm{~min}$. Sections then were washed through 2 changes of PBS over $20 \mathrm{~min}$ followed by 2 changes of $0.1 \mathrm{M}$ phosphate buffer for 20 min. For the demonstration of HRP, sections were reacted in $0.05 \%$ $\mathrm{DAB}$ and $0.01 \%$ hydrogen peroxide in $0.1 \mathrm{M}$ phosphate buffer containing $0.005 \%$ cobalt acetate/nickel chloride for 5-8 min. Most sections were rinsed through several changes of $0.1 \mathrm{M}$ phosphate buffer and were placed on pretreated microscope slides, dehydrated, and mounted with Permount for light microscopic examination using bright-field or Nomarski differential interference contrast optics. Some sections containing the abducens nucleus were postfixed in $1.0 \%$ osmium tetroxide and $1.5 \%$ potassium ferrocyanide in $0.1 \mathrm{M}$ phosphate buffer with $8 \%$ dextrose, staincd en bloc in $0.5 \%$ uranyl acetate in $0.05 \mathrm{M}$ malcate buffer, and processed for electron microscopy (May et al., 1987).

To provide a reference for the localization of glycine and GABA, the third group of sections was processed for the immunohistochemical localization of choline acetyltransferase (ChAT) as previously described (Beninato and Spencer, 1986). Sections were reacted with DAB-hydrogen peroxide with cobalt/nickel intensification and prepared for light microscopy.

Electrophysiology. Six cats were prepared for acute electrophysiological recordings in the abducens nucleus. Cats were anesthetized with sodium pentobarbital $(35-40 \mathrm{mg} / \mathrm{kg})$ administered intraperitoneally with supplemental doses $(2-10 \mathrm{mg} / \mathrm{kg} / \mathrm{hr}$, i.v.) given through a catheter in a foreleg vein. A tracheal cannula was inserted, and animals were mounted in a rigid head holder. Supplementary amino acid and electrolyte fluids were given to maintain the physiological condition of the animal. Bipolar silver wire stimulating electrodes were positioned bilaterally on the abducens nerve at the apex of the orbit and on the ampulla of the horizontal canal via a dorsal approach or on the horizontal canal nerve using a ventral approach through the tympanic bulla. Following a craniotomy, the posterior vermis of the cerebellum was aspirated to expose the floor of the IVth ventricle. Animals were paralyzed with gallamine triethiodide (2-4 mg/kg/hr, i.v.), artificial respiration was provided, and a bilateral pneumothorax was performed.

Extracellular antidromic and orthodromic field potentials were recorded with glass microelectrodes filled with $2 \mathrm{M}$ sodium chloride and having resistances of 3-5 M $\Omega$. Intracellular recordings were made using glass microelectrodes that contained $3 \mathrm{M}$ potassium chloride, $2 \mathrm{M}$ potassium citrate, or $2 \mathrm{M}$ lithium acetate with resistances of 10-20 M 2 . Microclcctrodes were attached to a Canberra-type micromanipulator and were lowered into the abducens nucleus using the facial colliculus as a landmark. Abducens motoneurons were identified by antidromic activation following electrical stimulation of the abducens nerve. Internuclear neurons were inferred by the absence of antidromic activation following VIth nerve stimulation, but, like the motoneurons, displayed the presence of reciprocal excitatory (EPSP) and inhibitory (IPSP) postsynaptic potentials following orthodromic vestibular nerve stimulation (Baker and Highstein, 1975). Conventional stimulation, amplification, and monitoring techniques were used. Data were stored on videocassette magnetic tape (NeuroData) and analyzed using an Analogic Data 6000 microcomputer.

The pharmacological antagonism of vestibular-evoked inhibition of abducens neurons was tested using picrotoxin, $2 \mathrm{mg} / \mathrm{ml}$ (Sigma), and strychnine nitrate, $0.2 \mathrm{mg} / \mathrm{ml}$ (Sigma), dissolved in isotonic saline. Picrotoxin and strychnine solutions were administered intravenously at doses of 0.1 and $1 \mathrm{mg} / \mathrm{kg}$, respectively.

\section{Results}

\section{Autoradiographic and HRP retrograde labeling of abducens} afferent neurons

Injections of ${ }^{3} \mathrm{H}$-glycine into the abducens nucleus produced diffuse, poorly defined labeling at the site of the injection (Fig. $1 A$ ). The region of effective high-affinity uptake and the extent of diffusion from the injection site, therefore, were difficult to assess. Most neurons within the abducens nucleus were lightly labeled with overlying silver grains. This labeling, however, appeared to represent low-affinity, nonspecific uptake by neurons and/or neuroglia in the vicinity of the injection site as a consequence of the longer postinjection survival period and the retention of soluble protein by glutaraldehyde fixation (Hökfelt and Ljungdahl, 1975; Cuénod et al., 1982). Low-affinity, nonspecific uptake was further indicated by labeling associated with the motoneuron axons in the descending course of the VIth nerve in the brain stem and by terminal labeling in the medial rectus subdivision of the oculomotor nucleus as a consequence of anterograde transport by the internuclear neurons. Despite this "background" labeling, which even with the smallest injections extended into neighboring structures (e.g., ipsilateral medial vestibular nucleus, reticular formation), densely labeled neurons still were discernible, particularly contralateral and up to several millimeters from the injection site.

The locations and distributions of neurons labeled autoradiographically by retrograde transport following an injection of ${ }^{3} \mathrm{H}$-glycine into the abducens nucleus are shown in Figure 2. Caudally, labeled neurons were observed in the prepositus hypoglossi nucleus, with contralateral predominance (Fig. 2, $A-$ $E$ ). Only a few prepositus neurons were labeled on the ipsilateral side. I abeled neurons were small in diameter and circular in shape, and were located principally in the ventral part of the nucleus and extending into the underlying reticular formation (Fig. 3A). Both the morphology and distribution of these contralateral prepositus neurons were similar to those labeled by retrograde transport of HRP from the abducens nucleus (Fig. $3 B$ ). However, injections of HRP into the abducens nucleus also labeled an approximately equivalent number of neurons in the ipsilateral prepositus nucleus that were located more dorsally in the nucleus. These neurons were not labeled by retrograde transport of ${ }^{3} \mathrm{H}$-glycine from the abducens nucleus.

At the rostral limit of the location of labeled neurons in the prepositus hypoglossi nucleus, a second population of neurons that were densely labeled by autoradiography following injection of ${ }^{3} \mathrm{H}$-glycine into the abducens nucleus was encountered in the contralateral dorsomedial medullary reticular formation. These neurons extended rostrally as a vertically oriented column along the lateral border of the MLF up to approximately the level of the midportion of the abducens nucleus (Fig. 2, $E-N$ ). A few labeled neurons were located within the neuronal boundary of the contralateral abducens nucleus. The labeled neurons were medium-diameter and predominantly multipolar or pyramidal in shape (Fig. 3C). Both the morphology and distribution of these neurons resembled that of neurons labeled by retrograde transport of HRP from the abducens nucleus (Fig. 3D). The dense autoradiographic labeling of this contralateral population of neurons in particular demonstrates the specificity of uptake 

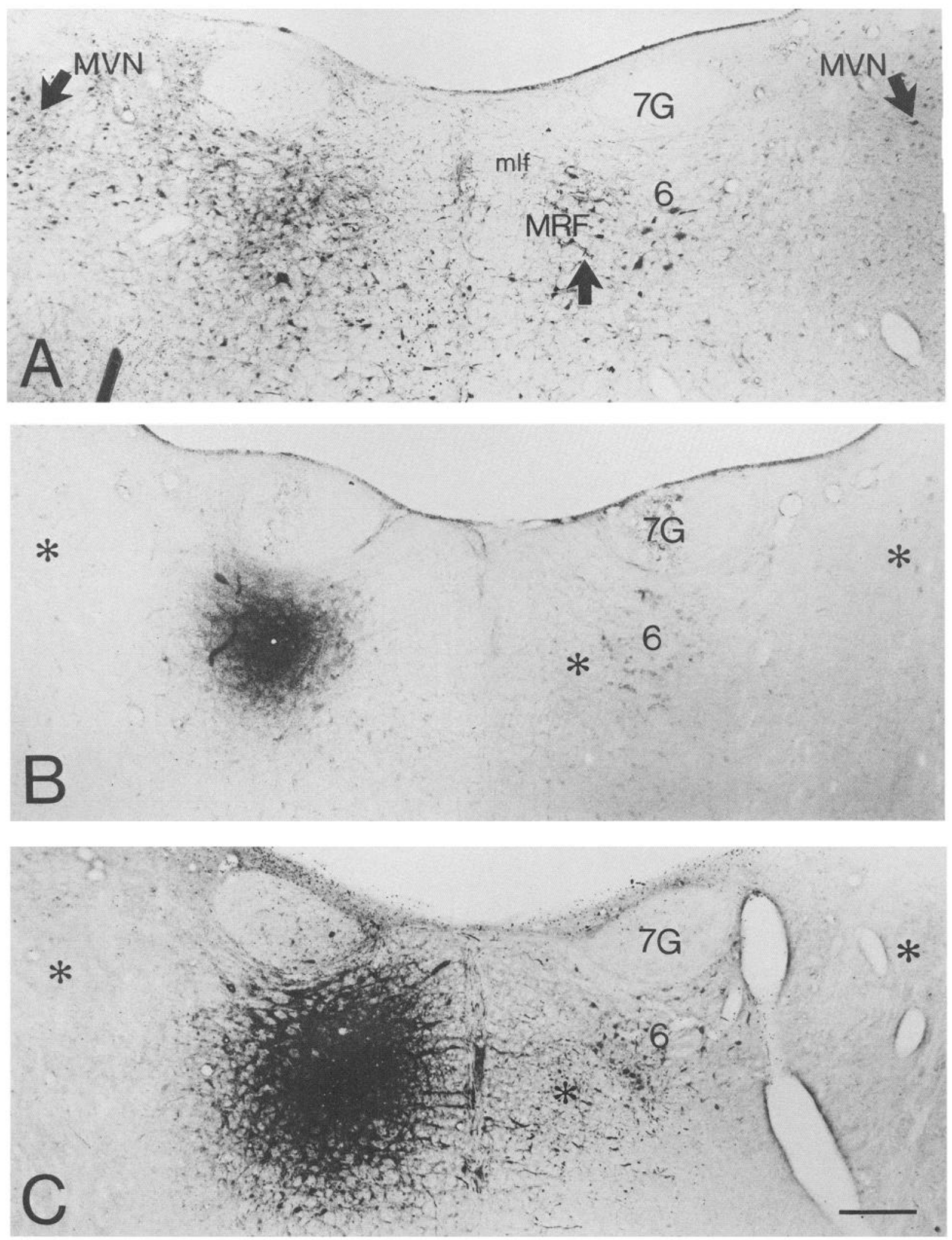

Figure 1. Bright-field photomicrographs of injection sites of ${ }^{3} \mathrm{H}$-glycine $(A),{ }^{3} \mathrm{H}$-GABA $(B)$, and ${ }^{3} \mathrm{H}$-leucine $(C)$ in the left abducens nucleus of the cat. In $A$, the injection site is poorly defined, but neurons autoradiographically labeled by retrograde transport of ${ }^{3} \mathrm{H}$-glycine (arrows) are seen in the ipsi- and contralateral medial vestibular nucleus $(M V N)$ and the contralateral dorsomedial medullary reticular formation $(M R F)$. Note that neurons in the corresponding ipsilateral reticular formation in close proximity to the injection site are not labeled. The injection sites of ${ }^{3} \mathrm{H}-\mathrm{GABA}$ $(B)$ and ${ }^{3} \mathrm{H}$-leucine $(C)$ are well defined, although no retrogradely labeled neurons are observed in the locations (asterisks) corresponding to those in $A$. In $C$, the axons of presumed abducens internuclear neurons are observed coursing toward the contralateral MLF. In all 3 experiments, the neuronal boundary of the abducens nucleus is demonstrated on the right side with the labeling of motoneurons by retrograde transport of HRP. Scale bar $(A-C), 1 \mathrm{~mm}$. 

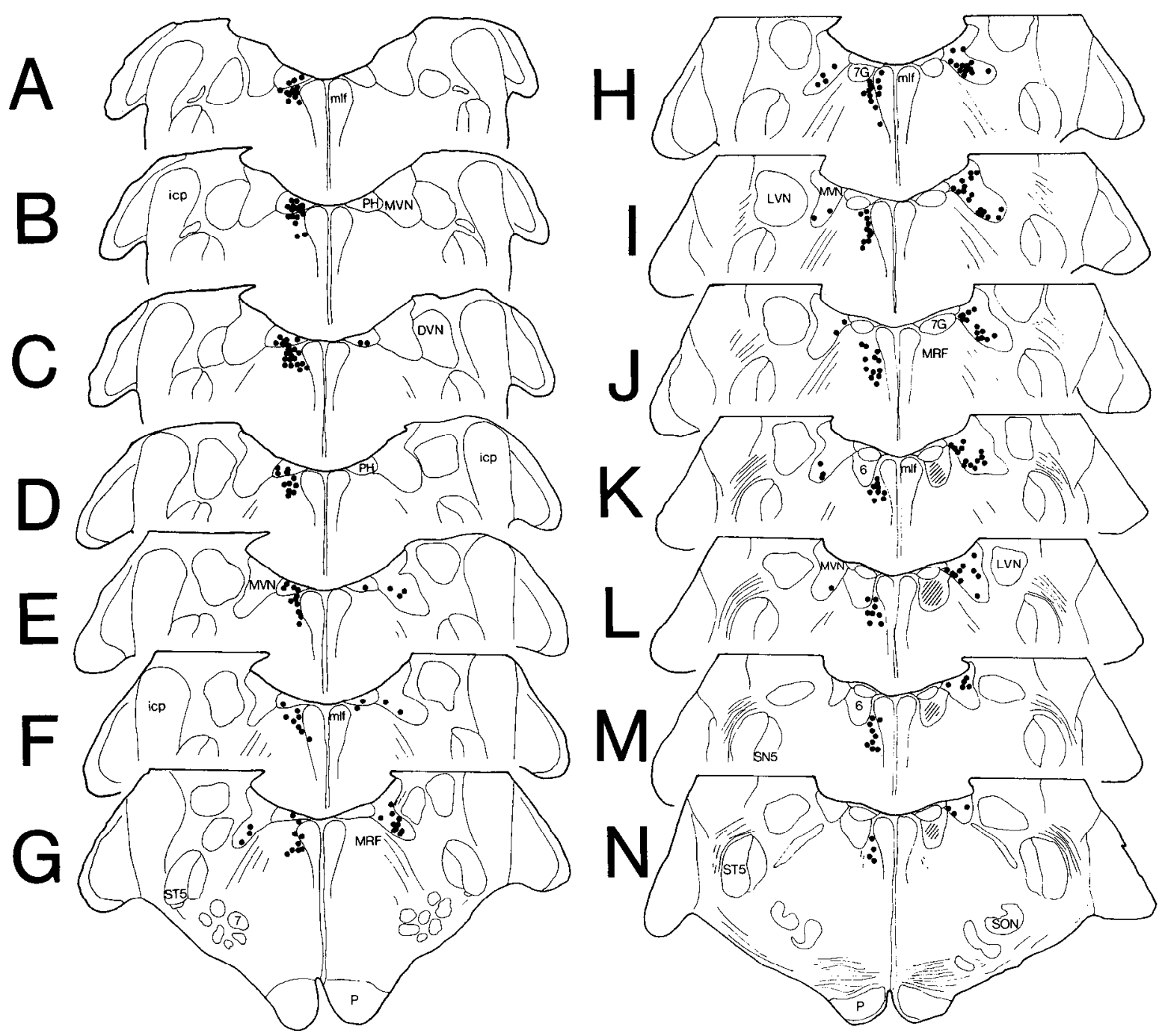

Figure 2. Charting of the locations of neurons in the posterior brain stem labeled autoradiographically by retrograde transport of ${ }^{3} \mathrm{H}$-glycine from the right abducens nucleus. Sections are arranged caudal $(A)$ to rostral $(N)$ at approximately $300 \mu \mathrm{m}$ intervals. The injection site is indicated by the shaded area in $K-N$.

and retrograde transport of ${ }^{3} \mathrm{H}$-glycine compared with the background level of labeling of this same population of neurons ipsilateral and in close proximity to the injection site, where local uptake by diffusion could have occurred.

A third population of neurons that were densely labeled autoradiographically by injection of ${ }^{3} \mathrm{H}$-glycine into the abducens nucleus was located in the medial vestibular nucleus (Fig. 2, E$N$ ), particularly in its ventrolateral extension (McCrea et al., 1980). In contrast to the labeled prepositus and dorsomedial medullary reticular neurons, these vestibular neurons were predominantly ipsilateral, with fewer neurons located in the contralateral nucleus (Fig. 2, G-L). Injections of HRP into the abducens nucleus, however, labeled approximately equivalent numbers of neurons in the ipsilateral and contralateral medial vestibular nuclei. The morphology of autoradiographically labeled neurons (Fig. 4, $A, C$ ) was similar to that of neurons labeled by retrograde transport of HRP (Fig. $4, B, D$ ). These medium-diameter neurons were ovoid in shape, with a slight elongation in the dorsomedial-ventrolateral axis.

In contrast to the findings obtained with ${ }^{3} \mathrm{H}$-glycine, injections of ${ }^{3} \mathrm{H}-\mathrm{GABA}$ into the abducens nucleus failed to retrogradely label any of the afferent neuronal populations that had been identified by retrograde transport of HRP. Even with large ( 0.5 $\mu \mathrm{l})$ injections and short $(2 \mathrm{hr}$ ) postinjection survival times, there was no evidence of labeled neurons in the neighboring ipsilateral medial vestibular nuclear or dorsomedial medullary reticular formation that might have incorporated ${ }^{3} \mathrm{H}$-GABA by diffusion from the injection site (Fig. 1B), as had been noted in similar experiments in the superior colliculus (Mize et al., 1981). The injection site was well defined with smaller amounts $(0.2 \mu \mathrm{l}$; Fig. $1 B$ ), but the pattern of labeling within the abducens nucleus was more consistent with low-affinity, nonspecific uptake by neuroglial cells than by synaptic endings, as noted in the oculomotor nucleus (Lanoir et al., 1982). Although low-affinity, nonspecific uptake by abducens neurons might have occurred, axonal or terminal labeling associated with the descending root of the VIth nerve or the contralateral oculomotor nucleus was not significantly above background. By contrast, injections of ${ }^{3} \mathrm{H}$-leucine produced dense autoradiographic labeling of both the motoneuron axons in their descending trajectory through the tegmentum and the internuclear neuron axons in the MLF and their termination in the contralateral oculomotor nucleus. Ret- 

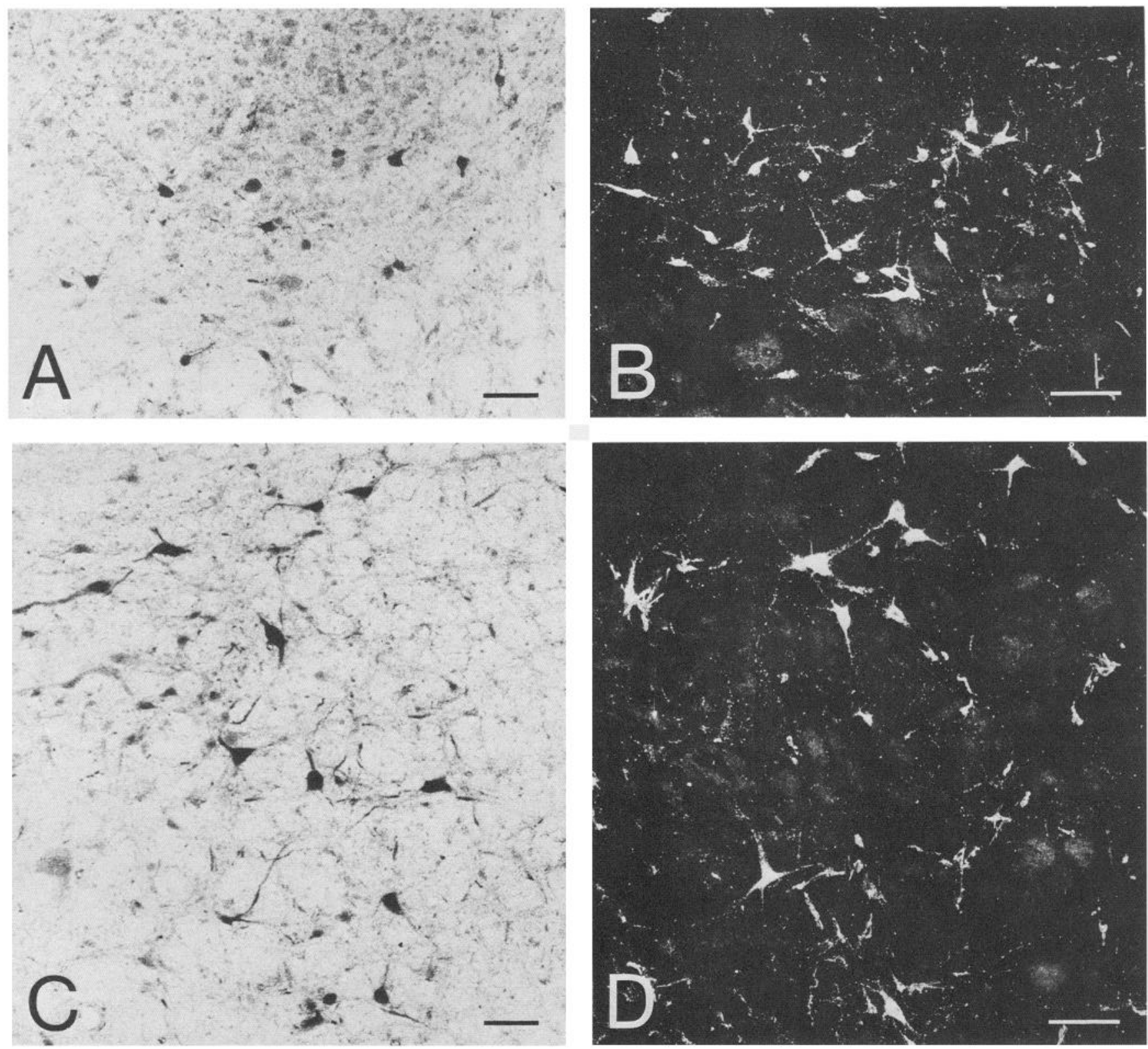

Figure 3. Bright-field $(A, C)$ and dark-field $(B, D)$ photomicrographs of retrogradely labeled neurons. Neurons in the contralateral prepositus hypoglossi nucleus labeled by retrograde transport of ${ }^{3} \mathrm{H}$-glycine $(A)$ or HRP $(B)$ from the abducens nucleus are located along the ventral border of the nucleus and extend into the underlying reticular formation. Further rostrally, neurons in the contralateral dorsomedial medullary reticular formation labeled by retrograde transport of ${ }^{3} \mathrm{H}$-glycine $(C)$ or HRP $(D)$ form a vertical column along the lateral margin of the MLF. The number, morphology, and distribution of neurons labeled by ${ }^{3} \mathrm{H}$-glycine and HRP are similar in both locations. Scale bars $(A-D), 50 \mu \mathrm{m}$.

rograde labeling of abducens afferent neurons using ${ }^{3} \mathrm{H}$-leucine, however, was not observed (Fig. 1C). These negative findings with ${ }^{3} \mathrm{H}-\mathrm{GABA}$ and ${ }^{3} \mathrm{H}$-leucine injections of the abducens nucleus demonstrate the selectivity of uptake and retrograde transport of ${ }^{3} \mathrm{H}$-glycine by specific populations of afferent neurons.

Two other populations of abducens afferent neurons were labeled by retrograde transport of HRP but were not labeled by either ${ }^{3} \mathrm{H}$-glycine or ${ }^{3} \mathrm{H}$-GABA. These neurons were located in the ipsilateral nucleus reticularis pontis caudalis ventral and rostral to the abducens nucleus and in the oculomotor nucleus and overlying supraoculomotor region, as also noted previously (Maciewicz et al., 1975, 1977; Langer et al., 1986; May et al., 1987). Since only short $(<12 \mathrm{hr})$ postinjection survival times were used with ${ }^{3} \mathrm{H}-\mathrm{GABA}$ to minimize its catabolism, however, the negative autoradiographic findings in relation to oculomotor internuclear neurons must be interpreted with caution.

\section{Immunohistochemical localization of glycine and GABA in the extraocular motor nuclei}

The immunohistochemical localization of glycine and GABA in the oculomotor, trochlear, and abducens nuclei revealed a differential density of immunoreactive staining both within and between the 3 regions. The motoneuron subdivisions of the oculomotor nucleus were identified with reference to their topographic organization (Akagi, 1978; Spencer et al., 1980; Miyazaki, 1985).

The immunohistochemical localization of glycine demonstrated a paucity of immunoreactive staining in association with 

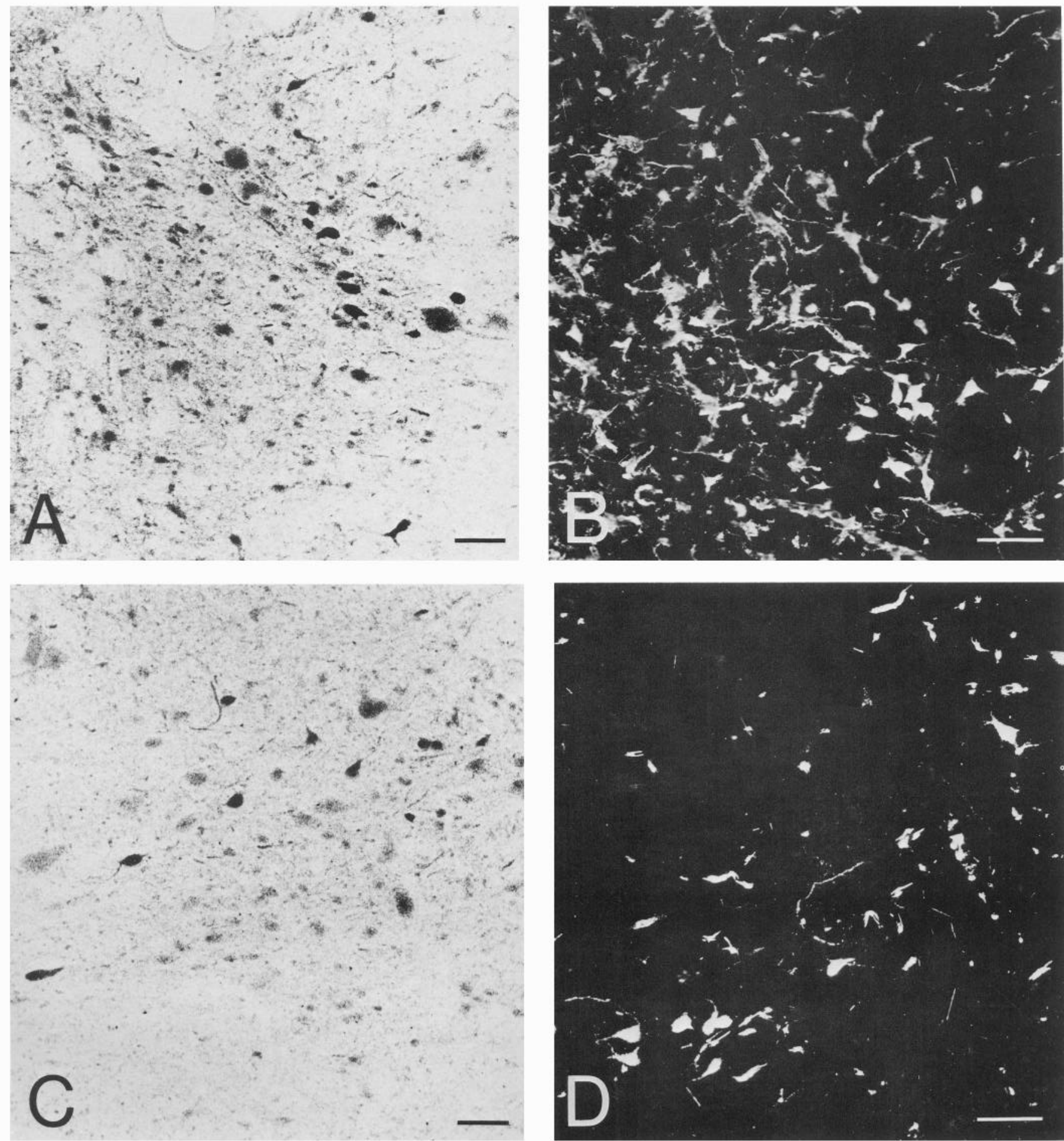

Figure 4. Bright-field $(A, C)$ and dark-field $(B, D)$ photomicrographs of retrogradely labeled neurons. Neurons in the ipsilateral medial vestibular nucleus labeled by retrograde transport of ${ }^{3} \mathrm{H}$-glycine $(A)$ or HRP $(B)$ from the abducens nucleus are located predominantly in the ventrolateral extension of the nucleus. Retrogradely labeled neurons in $B$ are partially obscured by reaction product associated with vasculature extending from the nearby injection site. In the contralateral medial vestibular nucleus, fewer neurons are labeled by retrograde transport of ${ }^{3} \mathrm{H}$-glycine $(C)$ than by HRP $(D)$. Scale bars $(A-D), 50 \mu \mathrm{m}$.

all motoneuron subgroups in the oculomotor (Fig. 5A) and trochlear (Fig. 5B) nuclei. Immunoreactive axons occasionally were observed, but synaptic boutons were difficult to resolve by light microscopy. By contrast, a high density of glycine-immunoreactive axons and boutons was observed in the abducens nucleus (Fig. 5C). Neurons and immunoreactive boutons were clustered in islands among fascicles of axons that traversed the nucleus both transversely and longitudinally, many of which also were immunoreactive. By electron microscopy, glycineimmunoreactive synaptic endings exhibited a widespread soma- 

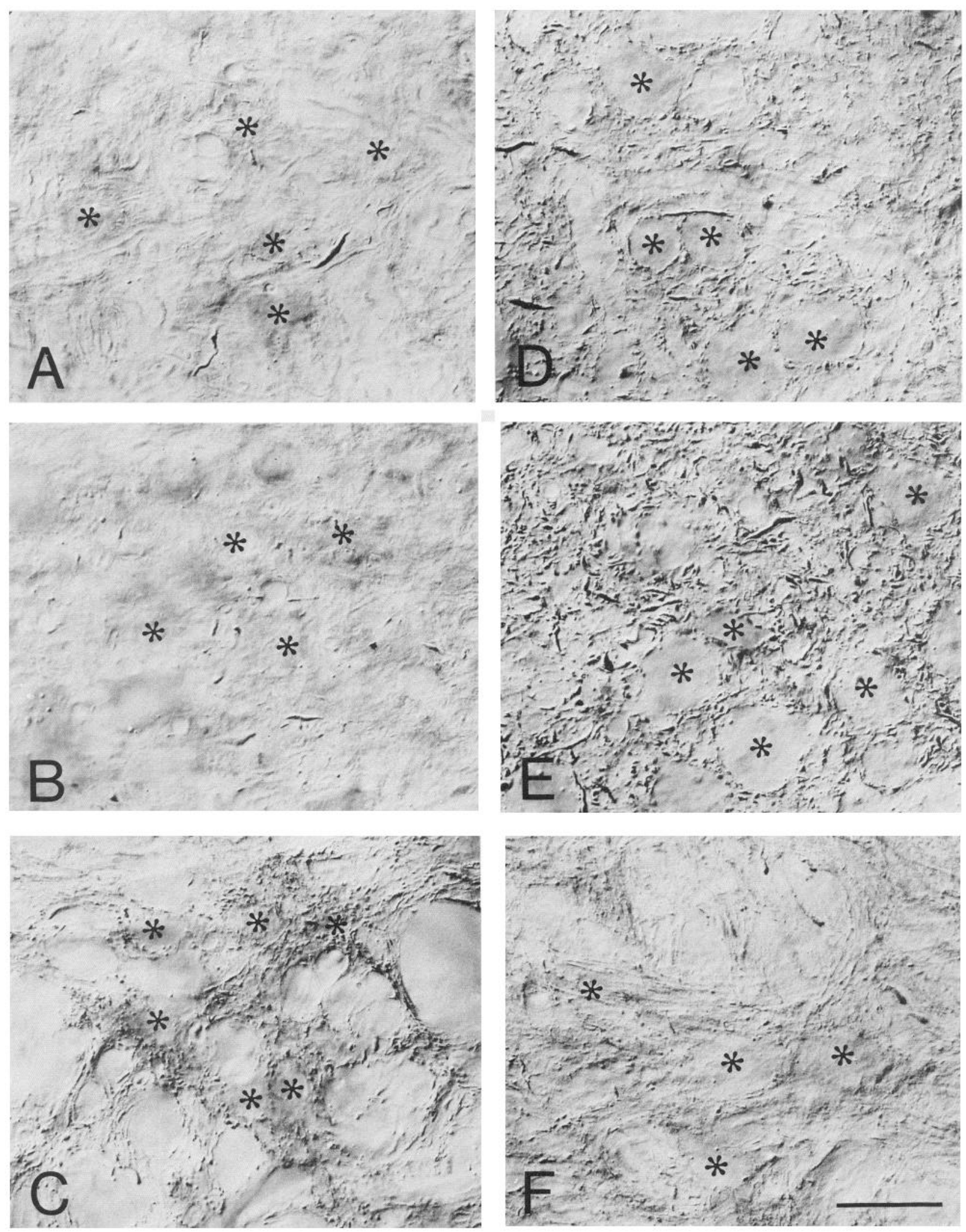

Figure 5. Nomarski differential interference contrast photomicrographs of glycine- $(A-C)$ and GABA- $(D-F)$ immunoreactive staining in the extraocular motor nuclei. Asterisks indicate neuronal somata. Both the oculomotor ( $A$; superior rectus and inferior oblique subdivisions) and trochlear $(B)$ nuclei exhibit sparse glycine-immunoreactive staining that is associated predominantly with a few axons. In the abducens nucleus (C), a high density of glycine-immunoreactive boutons is associated with neuronal somata and the surrounding neuropil. GABA-immunoreactive boutons are particularly prominent in association with the somata of motoneurons, as well as the surrounding neuropil in the superior rectus and inferior oblique subdivisions of the oculomotor nucleus $(D)$ and in the trochlear nucleus $(E)$. By contrast, the abducens nucleus $(F)$ exhibits a paucity of GABA-immunoreactive boutons in particular relation to neuronal somata. Scale bar $(A-F), 50 \mu \mathrm{m}$. 


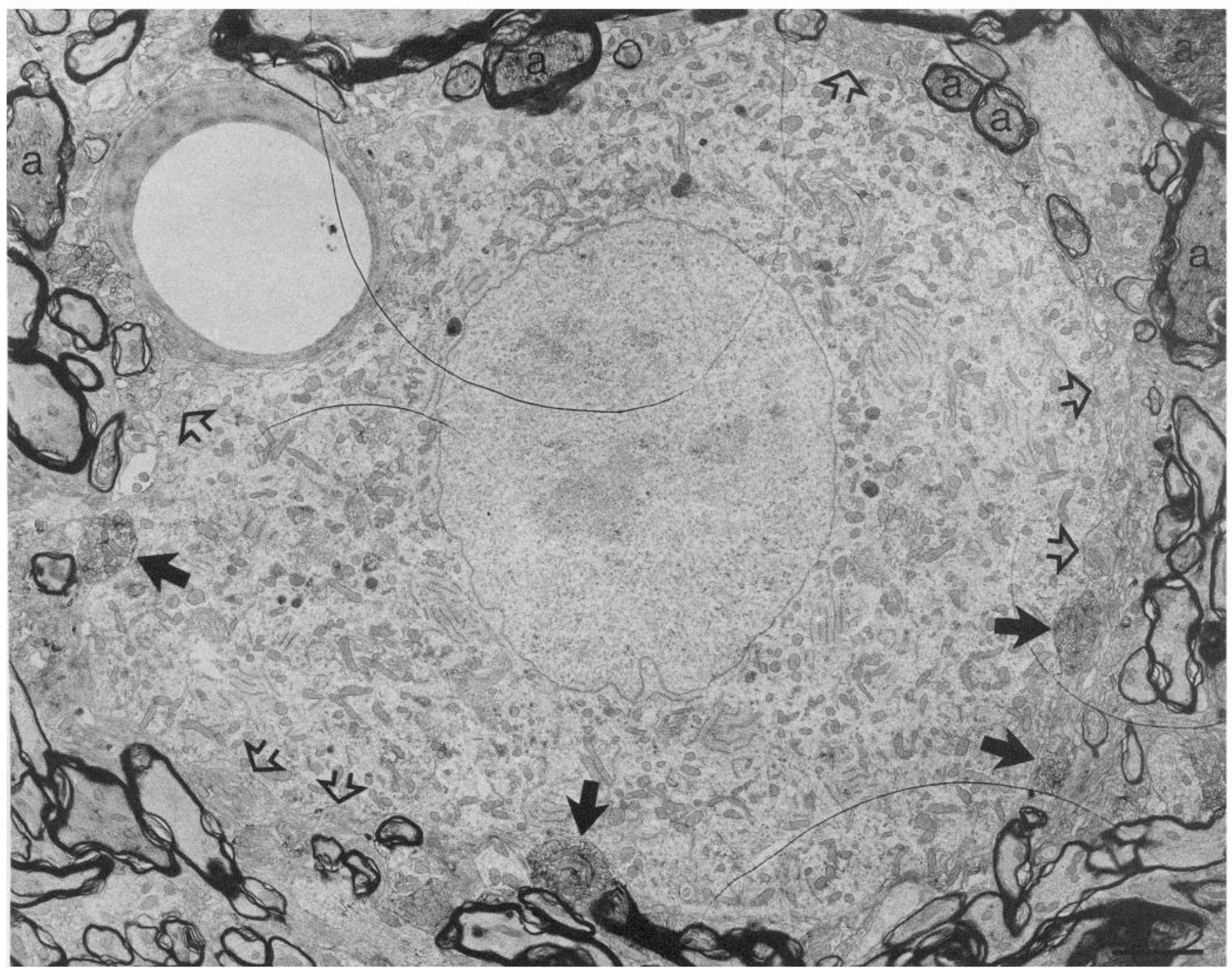

Figure 6. Electron micrograph of an abducens neuron with several glycine-immunoreactive synaptic endings (arrows) establishing axosomatic synaptic contacts. Nonimmunoreactive axosomatic synaptic endings are indicated by open arrows. Note also immunoreactive myelinated axons (a) in the surrounding neuropil. Scale bar, $2.5 \mu \mathrm{m}$.

dendritic distribution. Immunoreactive synaptic endings were prominent on the somata of abducens neurons and intermingled with other nonimmunoreactive synaptic endings (Figs. 6, 7B). In many instances, several immunoreactive synaptic endings were arranged as a closely spaced array on the soma (Fig. $7 \mathrm{~A}$ ). Immunoreactive synaptic endings also were encountered in the neuropil, where synaptic connections were established with large(Fig. 8A), medium-, and small-caliber (Fig. 8C) dendrites and dendritic spine-like appendages (Fig. $8, B, C$ ). Numerous immunoreactive myelinated axons also were observed in the neuropil (Figs. 6, 7A). There was a tendency for glycine-immunoreactive axosomatic synaptic endings to exhibit multiple short $(0.3-0.5 \mu \mathrm{m})$, spatially separated synaptic contact zones (Fig. $7 A$ ), similar to those characteristic of second-order vestibular synaptic endings in the oculomotor and trochlear nuclei (Spencer and Baker, 1983). Axodendritic immunoreactive synaptic endings, however, usually displayed only a single synaptic contact zone that extended much of the length (up to $1.3 \mu \mathrm{m}$ ) of the zone of apposition between the pre- and postsynaptic processes (Fig. 8, D, E). Synaptic contact zones were characterized by the accumulation of pleiomorphic synaptic vesicles along the presynaptic membrane, an inconspicuous postsynaptic membrane densification, and an intermediate dense line in the intercellular space (Fig. 8, $D-F$ ).

The immunohistochemical localization of GABA demonstrated a pattern of staining in the extraocular motor nuclei that contrasted with that of glycine. Within the oculomotor nucleus, GABA-immunoreactive staining was associated with preterminal and terminal boutons, many of which arose from immunoreactive axons in the dorsolateral region of the MLF. A moderate density of immunoreactive boutons was observed in the superior rectus, inferior oblique, and inferior rectus subdivisions of the nucleus in association with the motoneuron somata (Fig. 5D). GABA-immunoreactive boutons also were observed in the surrounding neuropil in these subdivisions. In the medial rectus subdivision, however, the motoneuron somata and surrounding neuropil were almost devoid of immunoreactive boutons. The trochlear nucleus exhibited the highest density of GABA-immunoreactive boutons (Fig. $5 E$ ). Many preterminal and terminal immunoreactive boutons arose from axons in 

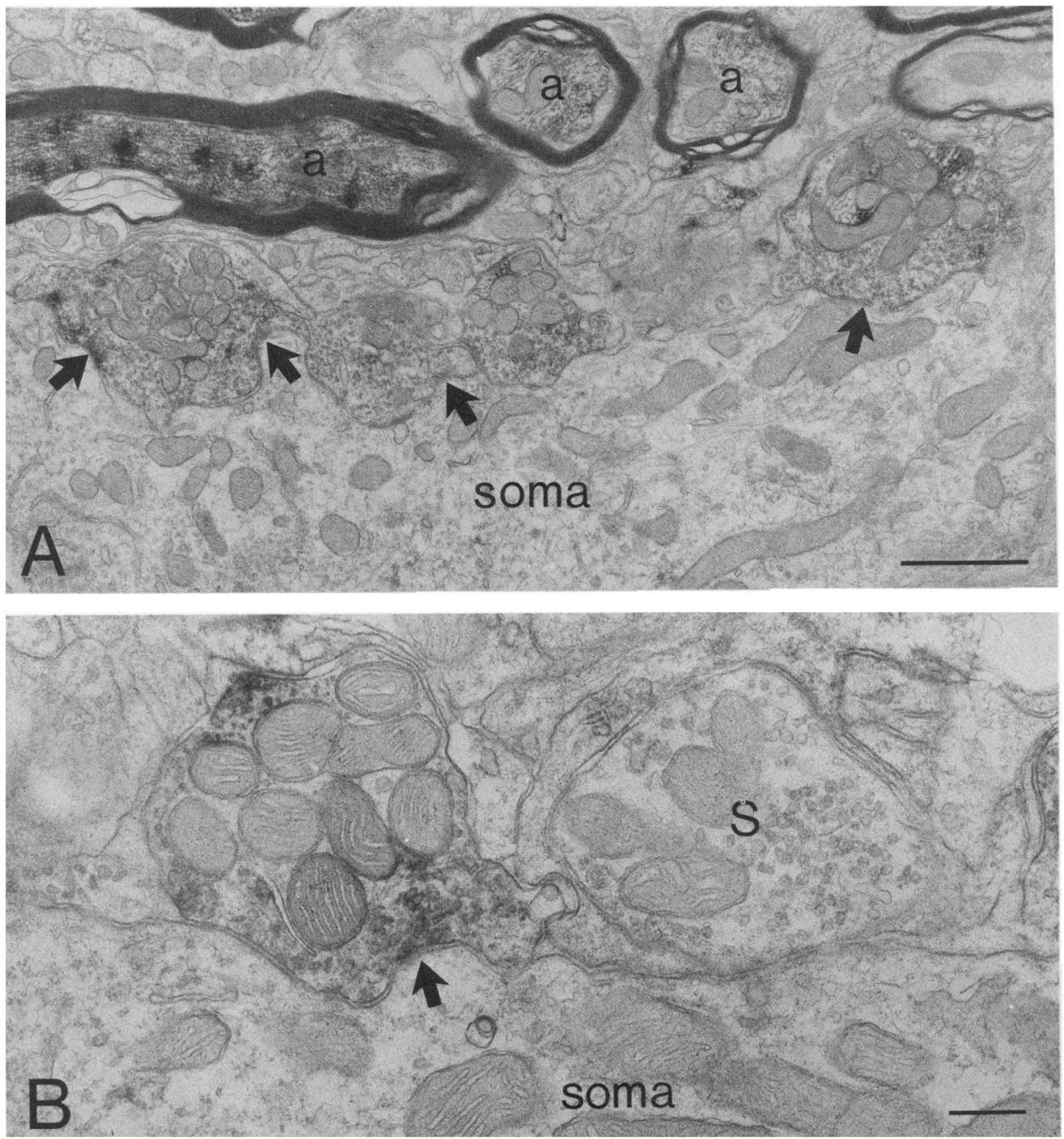

Figure 7. Electron micrographs of glycine-immunoreactive synaptic endings in the abducens nucleus. In $A$, a series of immunoreactive synaptic endings are associated with the soma of an abducens neuron, most establishing synaptic contacts (arrows). Immunoreactive myelinated axons also are seen in the immediate vicinity. In $B$, a glycine-immunoreactive axosomatic synaptic ending containing pleiomorphic synaptic vesicles exhibits a symmetrical pre-/postsynaptic membrane profile at the site of synaptic contact (arrow). The neighboring nonimmunoreactive synaptic ending $(S)$ contains predominantly spheroidal synaptic vesicles. Scale bars: $A, 1 \mu \mathrm{m} ; B, 0.25 \mu \mathrm{m}$.

the lateral portion of the MLF. GABA-immunoreactive boutons were distributed with high density on the somata and proximal dendrites of the motoneurons, as well as within the neuropil of the nucleus. By contrast, the abducens nucleus displayed a paucity of GABA-immunoreactive boutons in relation to the somata and proximal dendrites of the neurons (Fig. $5 F$ ). The few immunoreactive boutons that were observed were scattered in the neuropil of the nucleus. GABA-immunoreactive axons occupied fascicles passing through the nucleus, but there was no indication that any of these terminated within the nucleus.

The differential localization of glycine- and GABA-immunoreactive synaptic endings in the oculomotor, trochlear, and 

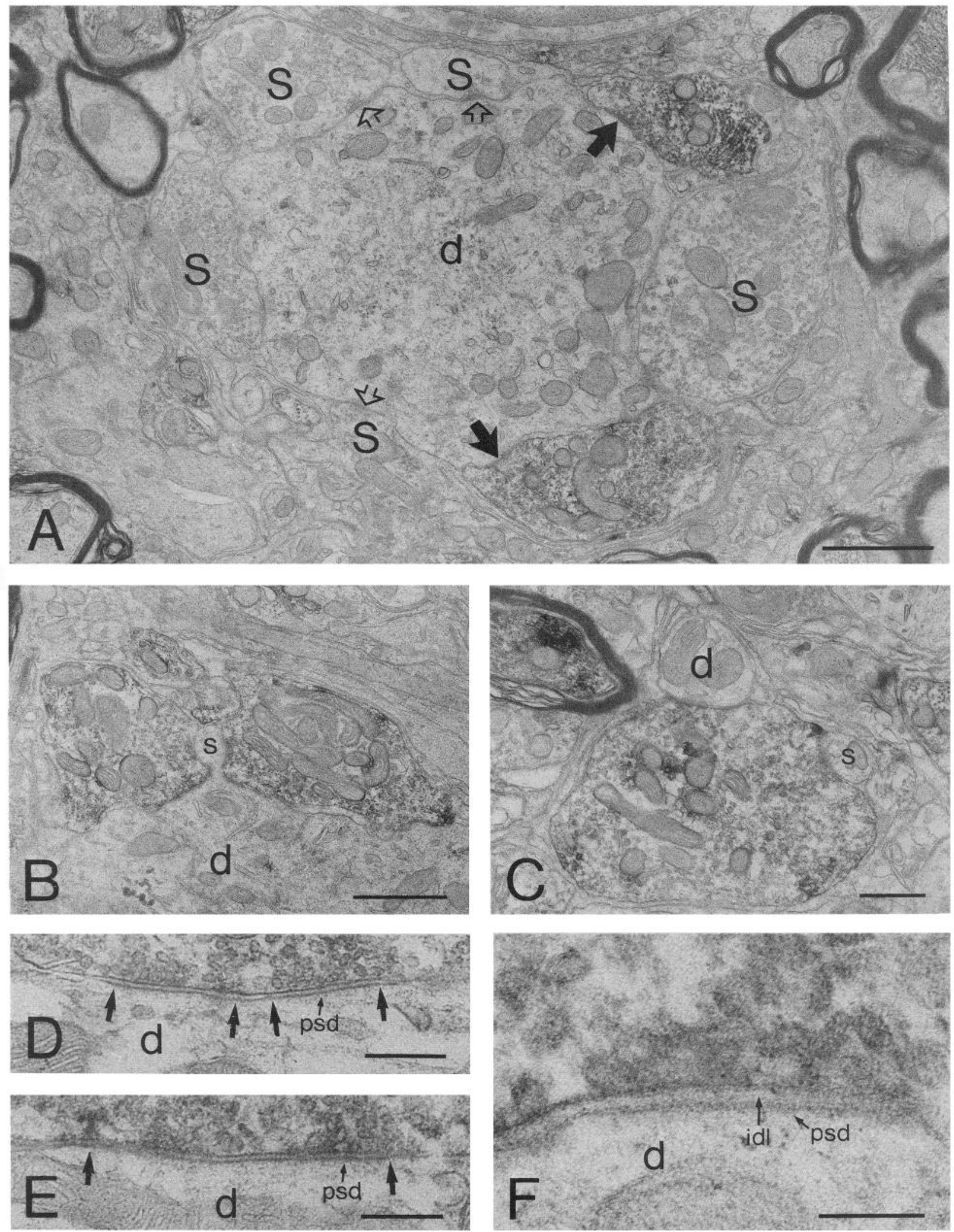

Figure 8. Electron micrographs of glycine-immunoreactive synaptic endings in the abducens nucleus. In $A, 2$ immunoreactive synaptic endings establish synaptic contacts (solid arrows) with the proximal dendrite $(d)$ of an abducens neuron. Nonimmunoreactive synaptic endings $(S)$ contain predominantly spheroidal synaptic vesicles and exhibit asymmetrical pre-/postsynaptic membrane profiles at sites of synaptic contact (open arrows). In $B$ and $C$, immunoreactive synaptic endings establish synaptic contacts with dendritic spinelike appendages $(s)$. The synaptic ending in $C$ also contacts a small-caliber dendrite $(d)$. Synaptic contact zones (extent indicated by paired arrows) in $D$ and $E$ are characterized by an accumulation of pleiomorphic synaptic vesicles along the presynaptic membrane and an inconspicuous postsynaptic membrane densification ( $p s d$ ). In $F$, the intermediate dense line $(i d l)$ in the intercellular space is characteristic of the synaptic contact zone. Scale bars: $A$ and $B, 1 \mu \mathrm{m} ; C, 0.5 \mu \mathrm{m} ; D$ and $E, 0.25 \mu \mathrm{m} ; F, 0.1 \mu \mathrm{m}$. 
abducens nuclei was correlated with differences in the immunoreactive staining of axons in the MLF at rostral and caudal levels of the brain stem. In the posterior brain stem at the level of ChAT-immunoreactive neurons in the caudal region of the prepositus hypoglossi nucleus (Fig. 9A), the MLF was characterized by a high density of glycine-immunoreactive axons, particularly in its lateral portion, as well as in the adjacent reticular formation (Fig. 9B). A paucity of GABA-immunoreactive axons, however, was observed at this level (Fig. $9 \mathrm{C}$ ). At the level of the abducens nucleus (Fig. 9D), glycine-immunoreactive axons were numerous in both the MLF and the nucleus itself (Fig. $9 E$ ), whereas few axons in the MLF at this level were GABAimmunoreactive (Fig. 9F). At the level of the trochlear nucleus (Fig. 9G), few axons in the MIF demonstrated immunoreactivity toward glycine (Fig. 9H). Numerous GABA-immunoreactive axons were arranged as fascicles in the lateral portion of the MLF among the terminal labeling associated with trochlear motoneurons (Fig. 9I).

In addition to glycine-immunoreactive axons, neurons in the posterior brain stem also demonstrated immunoreactivity toward glycine. Among other locations, glycine-immunoreactive neurons were observed in the caudal half of the prepositus hypoglossi nucleus, both clustered in the central portion of the nucleus, as well as located along its ventral margin (Fig. 10A). Glycine-immunoreactive neurons also were observed throughout the entire length of the medial vestibular nucleus, but particularly at rostral levels, where the nucleus is bisected by the acoustic stria with neurons extending ventrolaterally toward the ventral lateral vestibular nucleus (Fig. 10B). Finally, glycineimmunoreactive neurons were encountered in the dorsomedial medullary reticular formation medial and caudal to the abducens nucleus and lateral to the immunoreactive axons in the MLF (Fig. 10C).The locations of glycine-immunoreactive neurons in the prepositus hypoglossi and medial vestibular nuclei and in the dorsomedial medullary reticular formation were similar to the distribution of neurons labeled by retrograde transport of ${ }^{3} \mathrm{H}$-glycine from the abducens nucleus. The modest intensity of immunoreactive staining of these neurons in the absence of colchicine pretreatment compared with other locations (e.g., ventral cochlear nucleus), however, precluded an attempt to label the immunoreactive neurons in combination with retrogradely transported HRP from the abducens nucleus.

Pharmacological antagonism of vestibular-evoked inhibition in abducens motoneurons and internuclear neurons

Several different drug combinations and stimulation/recording paradigms were employed in the deeply anesthetized cat to specifically test the hypothesis based on the above autoradiographic and immunohistochemical findings that second-order inhibitory vestibular neurons that project to the ipsilateral abducens nucleus might utilize glycine as a neurotransmitter. Systemic administration of either the GABA antagonist picrotoxin, or the glycine antagonist strychnine, produced increases in heart rate and blood pressure that led to brain-stem pulsations. Consequently, prolonged intracellular recording was difficult. Thus, in 4 experiments extracellular field potential profiles recorded in the abducens nucleus were carefully examined. These data were confirmed in 2 fortunate experiments with continuous intracellular recordings from abducens motoneurons before and after strychnine administration.

Administration of picrotoxin at doses effective in blocking the extracellular postsynaptic positivity in the cat trochlear nu- cleus following VIIIth nerve stimulation $(2 \mathrm{mg} / \mathrm{kg}$; Precht et al., 1973) did not modify the extracellular field potential profile in the abducens nucleus (Fig. 11 $A$ ). Subsequent administration of strychnine in the same experiments produced a significant decrease in the extraccllular potential (Fig. 11B). These findings, however, do not provide conclusive pharmacological evidence, since electrical stimulation of the whole VIIIth nerve, including both the vestibular and cochlear divisions, evokes a nonspecific, open-field extracellular potential recorded both within and surrounding the abducens nucleus. In another experiment, an initial administration of strychnine $(2 \mathrm{mg} / \mathrm{kg})$ substantially decreased, but did not completely remove, the extracellular positivity (Fig. $12 A)$. Distinguishing between the pre- and postsynaptic positive peaks was compromised by the absence of a consistent change in amplitude (cf. Figs. $11 B$ and $12 A$ ).

By contrast, following selective electrical stimulation of only the horizontal canal nerve, the extracellular field potential profile was localized to the abducens nucleus and was nearly completely suppressed following administration of $2 \mathrm{mg} / \mathrm{kg}$ strychnine (Fig. 12B). In another experiment with selective horizontal canal nerve stimulation and administration of picrotoxin $(2 \mathrm{mg} /$ $\mathrm{kg}$ ), there was no reduction in the extracellular positivity.

The normal intracellular characteristics of vestibular-evoked IPSPs recorded in abducens motoneurons distinctly differed from those observed in trochlear motoneurons (Precht and Baker, 1972). The IPSPs recorded in abducens motoneurons exhibited a rapid rise time, shallow amplitude, and short time course (Fig. $13 \mathrm{~A}$; see also Baker et al., 1969b). At similar resting potentials, however, trochlear motoneuron IPSPs displayed much larger amplitudes (4- to 6-fold) and longer durations (2- to 3-fold). Irrespective of the extent to which these differences reflect terminal arborization and/or transmitter-receptor properties, the administration of strychnine $(2 \mathrm{mg} / \mathrm{kg})$ rapidly decreased both the rise time and amplitude of the IPSPs recorded in antidromically identified abducens motoneurons within 1-2 min (Fig. $13 B$ ). The IPSPs recorded in trochlear motoneurons, however, were never noticeably altered in these 2 aspects (unpublished observations). In 2 experiments, intracellular recordings sampled from many abducens motoneurons and internuclear neurons subsequent to strychnine administration demonstrated the absence of the typical IPSP waveform following ipsilateral horizontal canal nerve stimulation.

\section{Discussion}

The present study has demonstrated that specific populations of neurons in the medial vestibular and prepositus hypoglossi nuclei and in the dorsomedial medullary reticular formation are selectively labeled by uptake and retrograde transport of ${ }^{3} \mathrm{H}$ glycine, but not ${ }^{3} \mathrm{H}-\mathrm{GABA}$, from the abducens nucleus in the cat. The immunohistochemical localization of glycine has revealed a high density of immunoreactive synaptic endings in the abducens nucleus, whereas immunoreactive synaptic endings were sparse in the oculomotor and trochlear nuclei. By contrast, GABA-immunoreactive synaptic endings in the abducens nucleus are sparse but are present in high density in the oculomotor and trochlear nuclei. Glycine-immunoreactive neurons furthermore have been observed in the same brain-stem locations as neurons labeled by retrograde transport of ${ }^{3} \mathrm{H}$-glycine from the abducens nucleus. Electrophysiological studies have demonstrated that the vestibular-evoked inhibition of abducens motoneurons and internuclear neurons is effectively blocked by strychnine, a competitive antagonist of glycine, but 

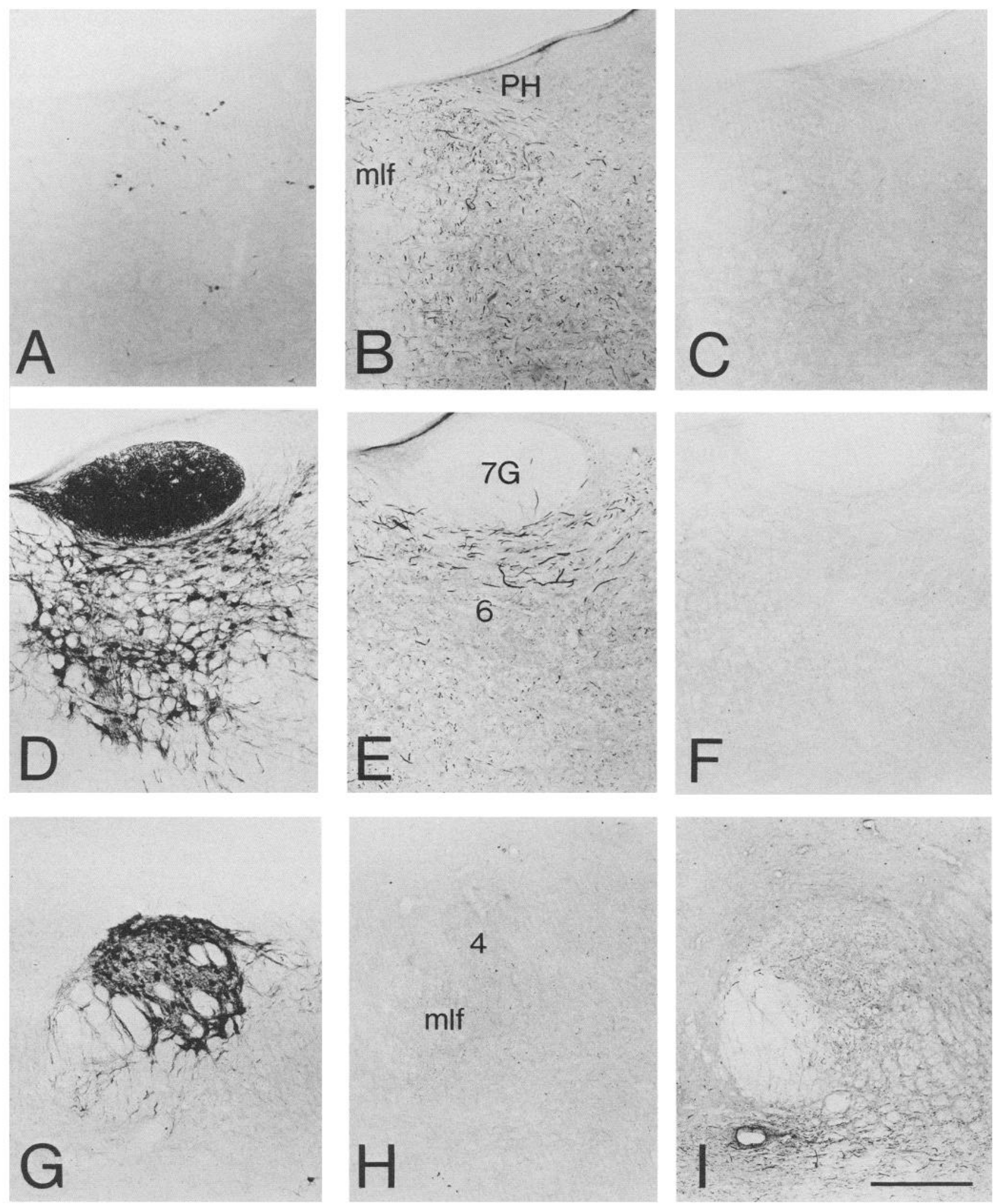

Figure 9. Bright-field photomicrographs of the immunohistochemical localization of ChAT, glycine, and GABA. In $A$, ChAT-immunoreactive neurons are located in the prepositus hypoglossi nucleus and scattered in the underlying reticular formation. Glycine-immunoreactive axons $(B)$ are located lateral in the descending MLF and in fascicles in the dorsal tegmentum. GABA-immunoreactive staining $(C)$ at this level is sparse. In the abducens nucleus, ChAT-immunoreactive neurons $(D)$ define the boundaries of the nucleus. Glycine-immunoreactive staining $(E)$ is associated with terminals and with axons that traverse the nucleus transversely and longitudinally. GABA-immunoreactive staining $(F)$ in the abducens nucleus is sparse. ChAT-immunoreactive staining in the trochlear nucleus $(G)$ is associated with the somata, dendrites, and axons of the motoneurons. Glycine-immunoreactive staining $(H)$ in the ascending MLF is associated with scattered axons, but terminal labeling in the trochlear nucleus is absent. By contrast, GABA-immunoreactive staining $(I)$ associated with terminals in the trochlear nucleus is dense, and GABA-immunoreactive axons occupy the lateral region of the MLF. Scale bar, $500 \mu \mathrm{m}$. 

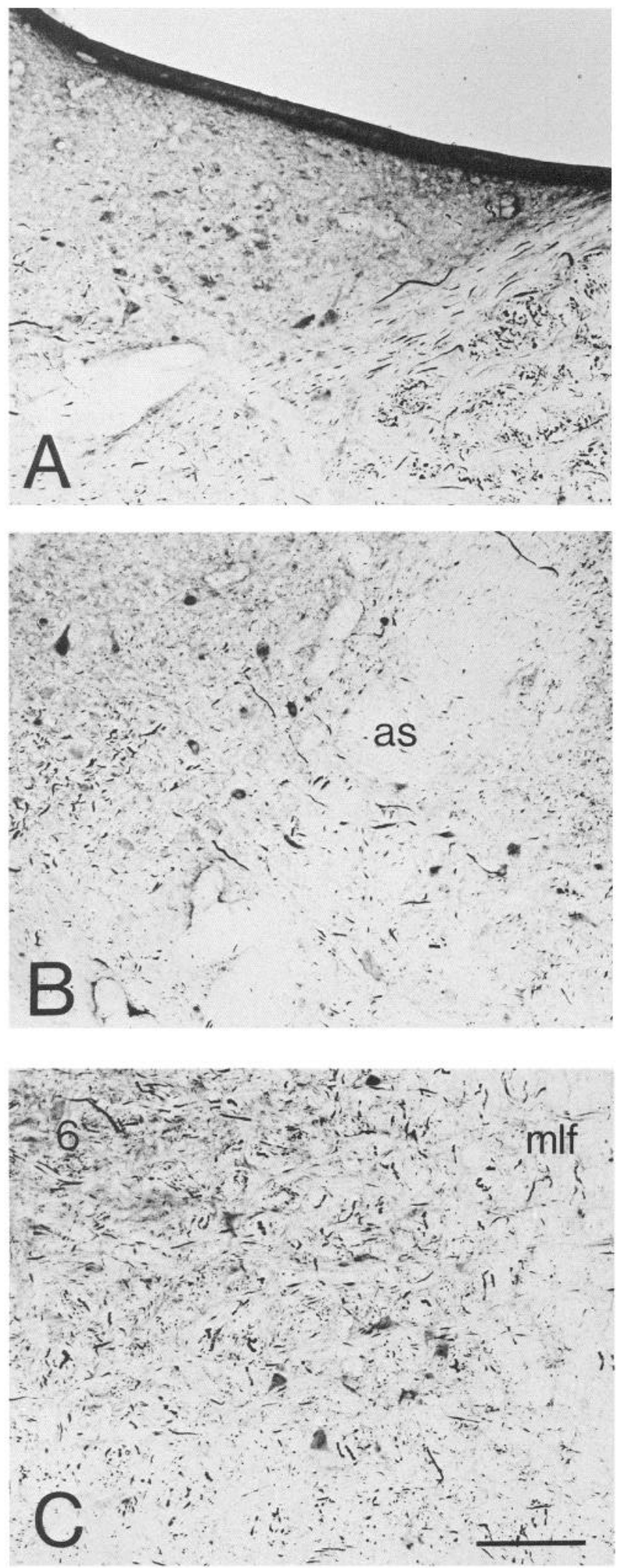

Figure 10. Bright-field photomicrographs of glycine-immunoreactive neurons. In the prepositus hypoglossi nucleus $(A)$ at approximately the same level as Figure $2 B$, immunoreactive neurons are located ventrally bordering the underlying reticular formation, as well as clustered in the central portion of the nucleus. In the medial vestibular nucleus $(B)$ at approximately the same level as Figure $2 I$, immunoreactive neurons is unaffected by picrotoxin, an antagonist of GABA. These findings, therefore, collectively suggest that glycine is the major inhibitory neurotransmitter utilized by brain-stem afferent neurons to the cat abducens nucleus.

The organization of reciprocal contralateral excitatory and ipsilateral inhibitory second-order vestibular synaptic connections with motoneurons in the oculomotor (Highstein, 1971, 1973a; Highstein et al., 1971; Berthoz et al., 1973; Baker and Berthoz, 1974; Ito et al., 1976a, b), trochlear (Highstein, 1971, 1973a; Precht and Baker, 1972), and abducens (Precht et al., 1967; Richter and Precht, 1968; Baker et al., 1969b; Highstein, 1973b; Baker and Highstein, 1975; Hikosaka et al., 1977; Uchino et al., 1979; Baker et al., 1980) nuclei is basically similar. The exception to this pattern is medial rectus motoneurons in the oculomotor nucleus, which rely extensively upon abducens internuclear input (Highstein and Baker, 1978) and a smaller direct excitatory vestibular input via the ascending tract of Deiters' (Baker and Highstein, 1978; Reisine and Highstein, 1979; Furuya and Markham, 1981; Reisine et al., 1981). Excitatory second-order vestibular neurons are located in all 4 (i.e., superior, medial, lateral, and inferior) vestibular nuclei (Highstein and Ito, 1971; Uchino et al., 1978, 1979, 1980, 1982; Yamamoto et al., 1978; Ishizuka et al., 1980; McCrea et al., 1980, 1987a, b; Graf et al., 1983; Isu and Yokota, 1983; Hirai and Uchino, 1984; Graf and Ezure, 1986; Highstein et al., 1987; Ohgaki et al., 1988). Inhibitory second-order vestibular neurons, however, are differentially segregated in 2 nuclei according to the semicircular canals to which they are related. Inhibitory vestibular neurons that are synaptically related to the anterior and posterior vertical canals are located in the superior vestibular nucleus (Highstein and Ito, 1971; Uchino et al., 1980, 1981, 1986; Graf et al., 1983; Mitsacos et al., 1983; Uchino and Suzuki, 1983; Graf and Ezure, 1986; Highstein et al., 1987), whereas those that are related to the horizontal canal are located in the medial vestibular nucleus (Uchino et al., 1979; McCrea et al., 1980, 1987; Ishizuka et al., 1980; Isu and Yokota, 1983; Uchino and Suzuki, 1983; Ohgaki et al., 1988). Previous studies have demonstrated that the inhibitory vestibular input to oculomotor (Ito et al., 1970; Obata and Highstein, 1970) and trochlear (Precht et al., 1973a) motoneurons is sensitive to bicuculline or picrotoxin antagonism, but is unaffected by strychnine. The high density of GABA-immunoreactive boutons, as well as of synaptic endings labeled by uptake of ${ }^{3} \mathrm{H}-\mathrm{GABA}$ (Lanoir et al., 1982), observed on the somata of oculomotor and trochlear neurons is correlated with the soma-dendritic distribution of ipsilateral second-order vestibular synaptic endings (Bak et al., 1976; Demêmes and Raymond, 1980; Spencer and Baker, 1983). Collectively, therefore, the evidence is rather compelling for a role of GABA as the predominant inhibitory neurotransmitter utilized in vertical vestibulo-ocular reflex connections.

The selective retrograde labeling of medial vestibular neurons with ${ }^{3} \mathrm{H}$-glycine from the abducens nucleus and the pharmacological antagonism of vestibular-evoked inhibition by strych-

are located both dorsomedial and ventrolateral to the acoustic stria (as). In the dorsomedial medullary reticular formation $(C)$ at approximately the same level as Figure $2 K$, immunoreactive neurons are located medial to the abducens nucleus $(6)$ and lateral to the MLF among numerous immunoreactive axons. Scale bar, $200 \mu \mathrm{m}$. 


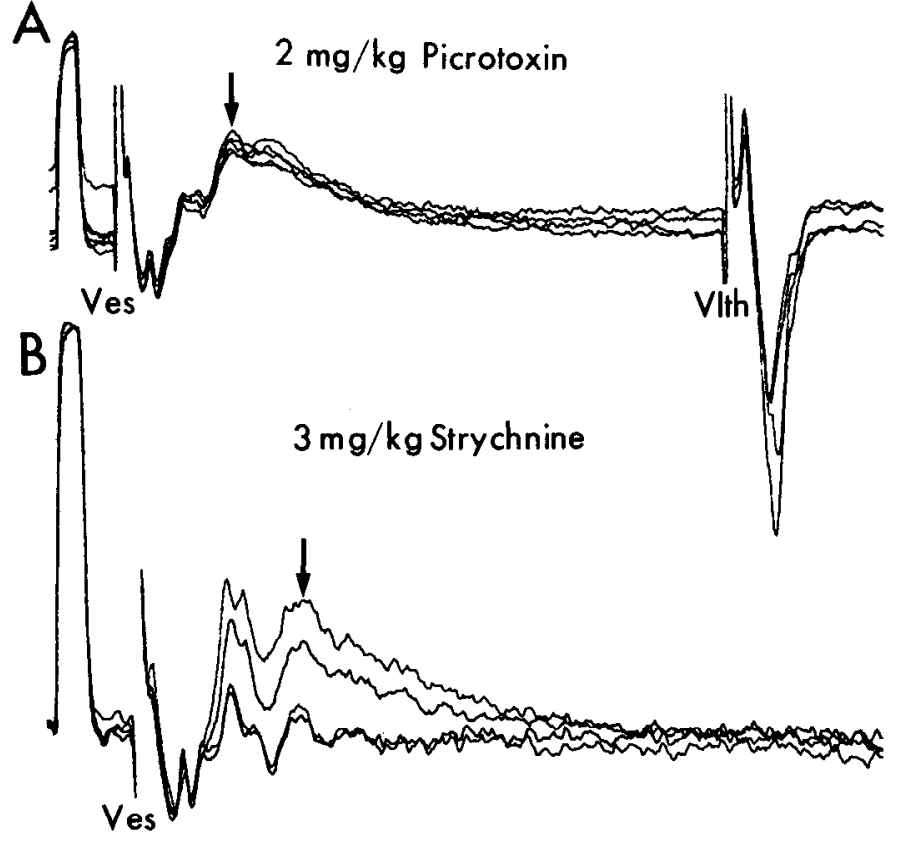

Figure 11. Effect of picrotoxin and strychnine on inhibitory postsynaptic field potentials in the abducens nucleus following vestibular nerve stimulation. $A$. Three records before and 2 following systemic administration of $2 \mathrm{mg} / \mathrm{kg}$ of picrotoxin. $B$, Two records before and 2 following systemic administration of $3 \mathrm{mg} / \mathrm{kg}$ of strychnine. Arrows at $2 \mathrm{msec}$ latency in $A$ and $B$ indicate the peak of the postsynaptic response. Each trace in $A$ and $B$ is the composite of 16 consecutive averaged sweeps. Calibrations: $1 \mathrm{mV}$ and $0.5 \mathrm{msec}$. Negative polarity is downward.

nine, however, suggest that glycine is the inhibitory neurotransmitter utilized in horizontal vestibulo-ocular reflex connections. The density and soma-dendritic distribution of glycine-immunoreactive boutons in the abducens nucleus furthermore correspond, at least in part, to the ipsilateral inhibitory vestibular input, which is distributed on the somata and proximal dendrites of the neurons (Ishizuka et al., 1980; Destombes and Rouvière, 1981; Ohgaki et al., 1988). In addition to synaptic connections with motoneurons in the extraocular motor nuclei that are related to the vestibulo-ocular reflex, second-order vestibular neurons that are related to the semicircular canals (Wilson and Maeda, 1974) and to the saccule and utricle (Wilson et al., 1977) also influence neck motoneurons in the cervical spinal cord, forming the basis of the vestibulo-collic reflex. The axons of horizontal canal-related inhibitory vestibular neurons that terminate in the ipsilateral abducens nucleus also have a descending branch that projects to the cervical spinal cord (McCrea et al., 1980). Correlated with the antagonism by strychnine of vestibular-evoked disynaptic IPSPs in cervical neck motoneurons (Felpel, 1972), a high density of glycine-immunoreactive synaptic endings and glycine receptors is located on the somata and proximal dendrites of ventral horn neurons in the cervical spinal cord (Triller et al., 1985, 1987; Geyer et al., 1987; van den Pol and Gorcs, 1988). The findings of the present study are therefore consistent with the role of glycine as the inhibitory neurotransmitter of horizontal canal-related second-order vestibular neurons in the vestibulo-ocular and vestibulo-collic reflexes.

Despite the evidence in favor of glycine as a neurotransmitter of inhibitory vestibulospinal connections, neurons in the rat medial and inferior vestibular nuclei that project to the spinal

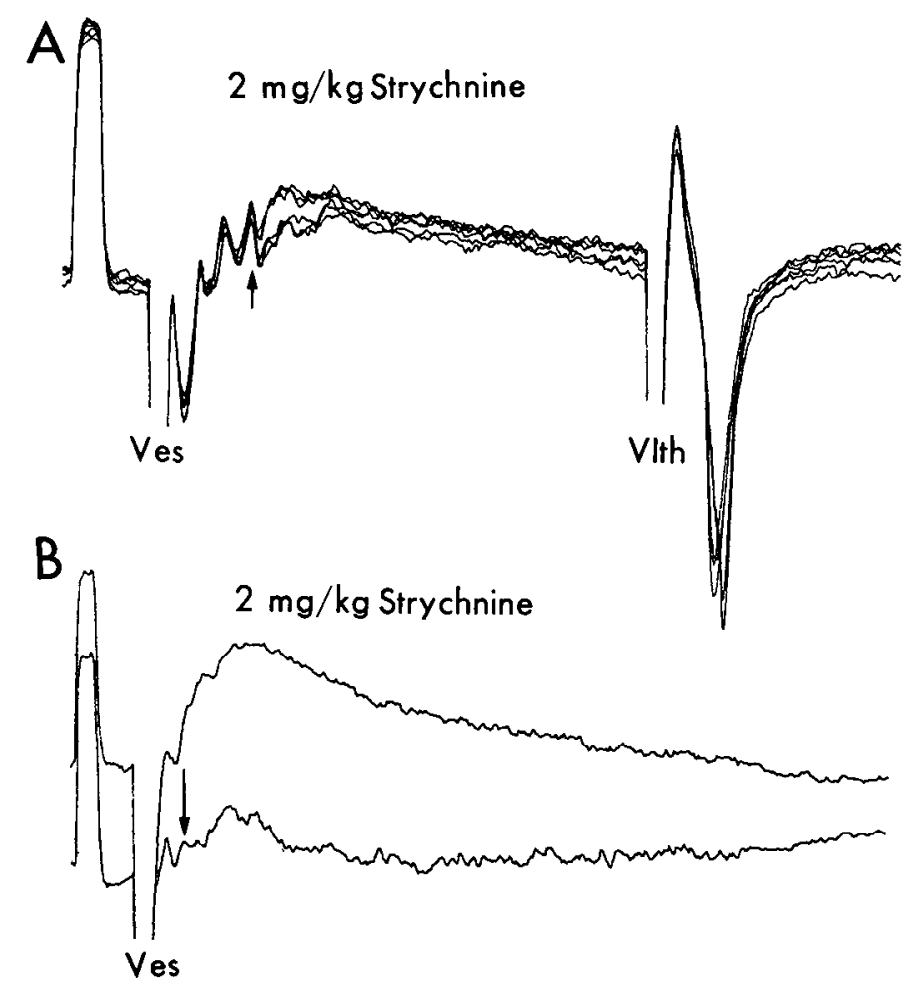

Figure 12. Effect of strychnine on vestibular-evoked inhibitory postsynaptic field potentials following electrical stimulation of the whole vestibular nerve $(A)$ or selective activation of the horizontal canal nerve $(B) . A$, Three records before and 2 following systemic administration of $2 \mathrm{mg} / \mathrm{kg}$ of strychnine. Arrow denotes onset of the postsynaptic field potential and demonstrates no drug effect on the presynaptic positivity. $B$, Selective horizontal canal nerve stimulation illustrates nearly complete abolition of the postsynaptic positive field potential (arrow) following systemic administration of $2 \mathrm{mg} / \mathrm{kg}$ of strychnine. Each trace in $A$ and $B$ is the average of 16 consecutive sweeps. Calibrations: $1 \mathrm{mV}$ and $0.5 \mathrm{msec}$ in $A, 1 \mathrm{msec}$ in $B$. Negative polarity is downward.

cord have been identified to be immunoreactive toward glutamate decarboxylase (GAD), the synthesizing enzyme of GABA (Blessing et al., 1987). Other studies in the rat (Nomura et al., 1984) and guinea pig (Kumoi et al., 1987) have identified GABAor GAD-immunoreactive neurons predominantly in the medial and inferior, and to a lesser extent superior, vestibular nuclei. In contrast to the findings in the present study, glycine-immunoreactive neurons previously have not been observed in the guinea pig vestibular nuclei (Peyret et al., 1987), although a very high density of glycine receptors has been localized in the extraocular motor nuclei (Araki et al., 1988). While the possibility exists that neurons may exhibit colocalization of GABA and glycine (Wenthold et al., 1987) or that GABAergic synaptic endings may be associated with glycine receptors (Triller et al., 1987), the disparities also might be explained by species differences and/or antibody specificity. The extent to which the present findings in the cat are applicable to other species is therefore unclear. Recent immunohistochemical studies in the rhesus monkey, however, demonstrate a pattern of glycine and GABA localization that is similar to that described here in the cat (unpublished observations).

The abducens nucleus also has reciprocal excitatory and inhibitory synaptic inputs from neurons in the pontomedullary reticular formation that are related to saccadic eye movements via connections with the superior colliculus (Grantyn et al., 
$1979,1980 \mathrm{~b})$. Premotor excitatory burst ncurons arc locatcd in the ipsilateral paramedian pontine reticular formation (nucleus reticularis pontis caudalis) ventral and rostral to the abducens nucleus (Büttner-Ennever and Henn, 1976; Highstein et al., 1976; Graybiel, 1977; Maciewicz et al., 1977; Grantyn et al., 1980a; Igusa et al., 1980; Curthoys et al., 1981; Kaneko et al., 1981; Langer et al., 1986; Strassman et al., 1986a). By contrast, inhibitory burst neurons are located in the contralateral dorsomedial medullary reticular formation medial and caudal to the abducens nucleus (Hikosaka and Kawakami, 1977; Maciewicz et al., 1977; Hikosaka et al., 1978; Hikosaka and Igusa, 1980; Yoshida et al., 1982; Langer et al., 1986; Strassman et al., 1986b; Belknap and McCrea, 1988; Scudder et al., 1988). In the present study, the location of neurons in the contralateral dorsomedial medullary reticular formation that are selectively labeled by retrograde transport of ${ }^{3} \mathrm{H}$-glycine from the abducens nucleus corresponds to that of the physiologically identified inhibitory burst neurons. The excitatory and inhibitory synaptic inputs from the pontomedullary reticular formation to cervical spinal cord motoneurons (Peterson et al., 1978) are organized similar to those to abducens neurons. The IPSPs in spinal motoneurons elicited by electrical stimulation of the reticular formation are effectively blocked by strychnine, suggesting that glycine is the inhibitory neurotransmitter of the descending reticulospinal inhibition (Llinás, 1964). The findings of the present study are thus consistent with the role of glycine as an inhibitory neurotransmitter of neurons in the medullary reticular formation that project to the abducens nucleus as well as those that project to the spinal cord.

The prepositus hypoglossi nucleus potentially represents one site of interaction between the visual and vestibular systems. Neurons in the prepositus have visual receptive fields and exhibit eye movement-related activity (Baker and Berthoz, 1975; Baker et al., 1976; Gresty and Baker, 1976; Blanks et al., 1977; López-Barneo et al., 1982). The anatomical basis of these response properties is attributable, at least in part, to afferent connections from the superior colliculus and the pretectal nucleus of the optic tract (Magnin et al., 1983) and extensive interconnections with the vestibular nuclei, the pontomedullary reticular formation, and the ccrcbcllum (McCrca and Baker, 1985; Belknap and McCrea, 1988). The prepositus also has efferent connections with the extraocular motor nuclei (Graybiel and Hartwieg, 1974; Baker et al., 1977; Graybiel, 1977; Maciewicz et al., 1977; Steiger and Büttner-Ennever, 1979; Hikosaka and Igusa, 1980; López-Barneo et al., 1981; McCrea and Baker, 1985; Langer et al., 1986; Belknap and McCrea, 1988). The findings of the present study suggest that the prepositus input to the contralateral abducens nucleus may be predominantly inhibitory and utilize glycine as a neurotransmitter. Presumably, most of the neurons in the ipsilateral prepositus nucleus that are labeled by retrograde transport of HRP, but not ${ }^{3} \mathrm{H}$-glycine, and that have a different distribution from those in the contralateral nucleus (see also Langer et al., 1986) are excitatory, like those that have synaptic connections with motoneurons in the oculomotor (López-Barneo et al., 1981) and trochlear (Baker et al., 1977) nuclei. The overwhelmingly contralateral predominance of neurons labeled by retrograde transport of ${ }^{3} \mathrm{H}$-glycine from the abducens nucleus is consistent with physiological findings that have demonstrated contralateral inhibitory and ipsilateral excitatory prepositus inputs to abducens motoneurons (Escudero and Delgado-García, 1988).

While glycine is a major inhibitory neurotransmitter in other
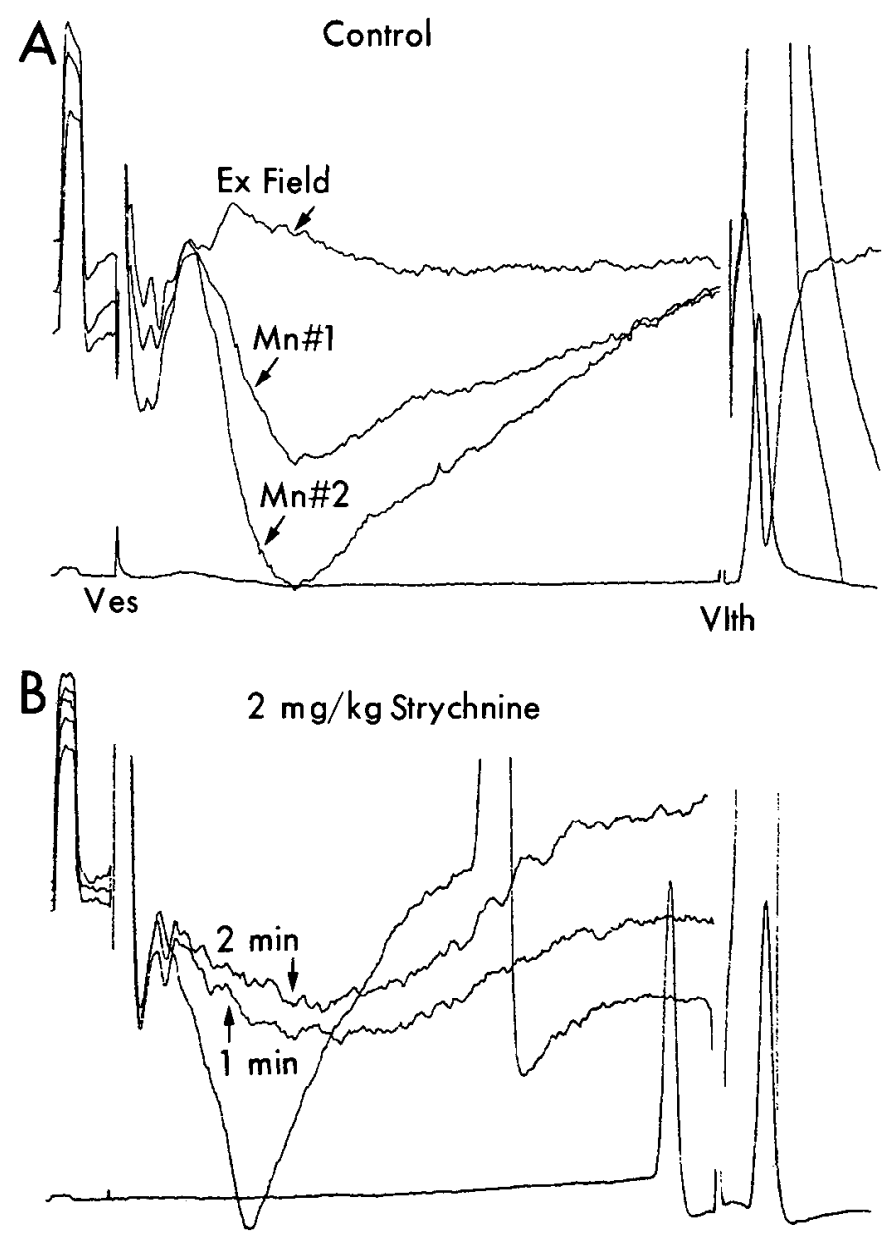

Figure 13. Intracellular records from abducens motoneurons following vestibular nerve stimulation and systemic administration of $2 \mathrm{mg} / \mathrm{kg}$ strychnine. $A$, Normal representative synaptic potentials in 2 motoneurons illustrating the rise time, amplitude, and half-width of IPSPs, and immediate extracellular field potential. Each record is the average of 8 consecutive traces. $B$, Intracellular records from an abducens motoneuron 1 and $2 \mathrm{~min}$ following systemic administration of $2 \mathrm{mg} / \mathrm{kg}$ strychnine. There is a rapid decrease in the rise time and peak amplitude of the IPSP and a less prominent decrease in half-width. Calibrations: 1 $\mathrm{mV}$ and $0.5 \mathrm{msec}$ in $A, 1 \mathrm{msec}$ in $B$. Negative polarity is downward.

cranial nerve motor nuclei (Frostholm and Rotter, 1985; Araki et al., 1988) and the spinal cord ventral horn (Young and Macdonald, 1983) a paradox is apparent in the mediation of inhibition in the extraocular motor nuclei by functionally equivalent populations of neurons. The findings in the present study suggest that glycine is the putative inhibitory neurotransmitter of premotor neurons that are related to the horizontal vestibulo-ocular reflex. By contrast, GABA may be the neurotransmitter of second-order inhibitory vestibular neurons that are related to the vertical semicircular canals and that establish synaptic connections with oculomotor and trochlear motoneurons. Glycine also is the likely neurotransmitter of inhibitory burst neurons that are related to horizontal saccadic cyc movements and of a class of prepositus hypoglossi neurons that project to the abducens nucleus. Despite the negative autoradiographic findings with ${ }^{3} \mathrm{H}$ GABA, however, there is a comparatively modest GABA-immunoreactive synaptic input to the cat abducens nucleus whose source is presently unknown. One interesting possibility is that this GABAergic input may be derived from internuclear neurons 
in the oculomotor nucleus (Maciewicz and Spencer, 1977; May et al., 1987), which, like all of the other inputs (i.e., vestibular, reticular, prepositus) to the abducens nucleus, has both excitatory and inhibitory components (Maciewicz et al., 1975).

\section{References}

Akagi, Y. (1978) The localization of the motor neurons innervating the extraocular muscles in the oculomotor nuclei of the cat and rabbit, using horseradish peroxidase. J. Comp. Neurol. 181: 745-762.

Araki, T., M. Yamano, T. Murakami, A. Wanaka, H. Betz, and M. Tohyama (1988) Localization of glycine receptors in the rat central nervous system: An immunocytochemical analysis using monoclonal antibody. Neuroscience 25:613-624.

Bak, I. J., R. Baker, W. B. Choi, and W. Precht (1976) Electron microscopic investigation of the vestibular projection to the cat trochlear nuclei. Neuroscience $1: 477-482$.

Baker, R., and A. Berthoz (1974) Organization of vestibular nystagmus in oblique oculomotor system. J. Neurophysiol. 37: 195-217.

Baker, R., and A. Berthoz (1975) Is the prepositus hypoglossi nucleus the source of another vestibulo-ocular pathway? Brain Res. 86: 121127 .

Baker, R., and S. M. Highstein (1975) Physiological identification of interneurons and motoneurons in the abducens nucleus. Brain Res. 91: 292-298

Baker, R., and S. M. Highstein (1978) Vestibular projections to medial rectus subdivision of oculomotor nucleus. J. Neurophysiol. 41: 16291646.

Baker, R., and W. Precht (1972) Electrophysiological properties of trochlear motoneurons as revealed by IVth nerve stimulation. Exp. Brain Res. 14: 127-157.

Baker, R. G., N. Mano, and H. Shimazu (1969a) Intracellular recording of antidromic responses from abducens motoneurons in the cat. Brain Res. 15: 573-576.

Baker, R. G., N. Mano, and H. Shimazu (1969b) Postsynaptic potentials in abducens motoneurons induced by vestibular stimulation. Brain Res. 15: 577-580.

Baker, R., M. Gresty, and A. Berthoz (1976) Neuronal activity in the prepositus hypoglossi nucleus correlated with vertical and horizontal eye movement in the cat. Brain Res. 101: 366-371.

Baker, R., A. Berthoz, and J. Delgado-García (1977) Monosynaptic excitation of trochlear motoneurons following electrical stimulation of the prepositus hypoglossi nucleus. Brain Res. 121: 157-161.

Baker, R., R. A. McCrea, and R. F. Spencer (1980) Synaptic organization of cat "accessory" abducens motoneurons. J. Neurophysiol. 43: 771-790.

Baker, R., W. Graf, and R. F. Spencer (1982) The vertical vestibuloocular reflex. In Physiological and Patholological Aspects of Eye Movements, A. Roucoux and M. Crommelinck, eds., pp. 101-116, Dr W. Junk, The Hague.

Belknap, D. B., and R. A. McCrea (1988) Anatomical connections of the prepositus and abducens nuclei in the squirrel monkey. J. Comp. Neurol. 268: 13-28.

Beninato, M., and R. F. Spencer (1986) A cholinergic projection to the rat superior colliculus demonstrated by retrograde transport of horseradish peroxidase and choline acetyltransferase immunohistochemistry. J. Comp. Neurol. 253: 525-538.

Berthoz, A., R. Baker, and W. Precht (1973) Labyrinthine control of inferior oblique motoneurons. Exp. Brain Res. 18: 225-241.

Blanks, R. H. I., R. Volkind, W. Precht, and R. Baker (1977) Responses of cat prepositus hypoglossi neurons to horizontal angular acceleration. Neuroscience $2: 391-403$

Blessing, W. W., S. C. Hedger, and W. H. Oertel (1987) Vestibulospinal pathway in rabbit includes GABA-synthesizing neurons. Neurosci. Lett. 80: 158-162.

Büttner-Ennever, J. A., and V. Henn (1976) An autoradiographic study of the pathways from the pontine reticular formation involved in horizontal eye movements. Brain Res. 108: 155-164.

Carleton, S. C., and M. B. Carpenter (1983) Afferent and efferent connections of the medial, inferior and lateral vestibular nuclei in the cat and monkey. Brain Res. 278: 29-51.

Carpenter, M. B., and R. R. Batton III (1980) Abducens internuclear neurons and their role in conjugate horizonlal gaze. J. Comp. Neurol. 189: 191-209.
Carpenter, M. B., and S. C. Carleton (1983) Comparison of vestibular and abducens internuclear projections to the medial rectus subdivision of the oculomotor nucleus in the monkey. Brain Res. 274: 144149 .

Carpenter, M. B., and R. J. Cowie (1985) Connections and oculomotor projections of the superior vestibular nucleus and cell group ' $y$.' Brain Res. 336: 265-287.

Cuénod, M., P. Bagnoli, A. Beaudet, A. Rustioni, L. Wiklund, and P. Streit (1982) Transmitter-specific retrograde labeling of neurons. In Cytochemical Methods in Neuroanatomy, V. Chan-Palay and S. L. Palay, eds., pp. 17-44, Liss, New York.

Curthoys, I. S., S. Nakao, and C. H. Markham (1981) Cat medial pontine reticular neurons related to vestibular nystagmus: Firing pattern, location and projection. Brain Res. 222: 75-94

Demêmes, D., and J. Raymond (1980) Identification des terminaisons vestibulaires dans les noyaux oculomoteurs communs chez le chat par radioautographie en microscopie electronique. Brain Res. 196: $331-345$.

Destombes, J., and A. Rouvière (1981) Ultrastructural study of vestibular and reticular projections to the abducens nucleus. Exp. Brain Kes. 43: 253-260.

Escudero, M., and J. M. Delgado-García (1988) Behavior of reticular, vestibular and prepositus neurons terminating in the abducens nucleus of the alert cat. Exp. Brain Res. 71: 218-222.

Felpel, L. P. (1972) Effects of strychnine, bicuculline and picrotoxin on labyrinthine-evoked inhibition in neck motoneurons of the cat. Exp. Brain Res. 14: 494-502.

Frostholm, A., and A. Rotter (1985) Glycine receptor distribution in mouse CNS: Autoradiographic localization of $\left[{ }^{3} \mathrm{H}\right]$ strychnine binding sites. Brain Res. Bull. 15: 473-486.

Furuya, N., and C. H. Markham (1981) Arborization of axons in oculomotor nucleus identified by vestibular stimulation and intraaxonal injection of horseradish peroxidase. Exp. Brain Res. 43: 289303.

Gacek, R. R. (1971) Anatomical demonstration of the vestibulo-ocular projections in the cat. Acta Otolaryngol. Suppl. 293: 1-63.

Gacek, R. R. (1977) Location of brain stem neurons projecting to the oculomotor nucleus in the cat. Exp. Neurol. 57: 725-749.

Gacek, R. R. (1979) Location of abducens afferent neurons in the cat. Exp. Neurol. 64: 342-353.

Geyer, S. W., W. Gudden, H. Betz, H. Gnahn, and A. Weindl (1987) Co-localization of choline acetyltransferase and postsynaptic glycine receptors in motoneurons of rat spinal cord demonstrated by immunocytochemistry. Neurosci. Lett. 82: 11-15.

Graf, W., and K. Ezure (1986) Morphology of vertical canal related second order vestibular neurons in the cat. Exp. Brain Res. 63: 3548.

Graf, W., R. A. McCrea, and R. Baker (1983) Morphology of posterior canal related secondary vestibular neurons in rabbit and cat. Exp. Brain Res. 52: 125-138.

Grantyn, A., R. Grantyn, K.-P. Robine, and A. Berthoz (1979) Electroanatomy of tectal efferent connections related to eye movements in the horizontal plane. Exp. Brain Res. 37: 149-172.

Grantyn, R., R. Baker, and A. Grantyn (1980a) Morphological and physiological identification of excitatory pontine reticular neurons projecting to the cat abducens nucleus and spinal cord. Brain Res. 198: 221-228.

Grantyn, A., R. Grantyn, U. Gaunitz, and K.-P. Robine (1980b) Sources of direct excitatory and inhibitory inputs from medial rhombencephalic tegmentum to lateral and medial rectus motoneurons in the cat. Exp. Brain Res. 39: 49-61.

Graybiel, A. M. (1977) Direct and indirect preoculomotor pathways of the brainstem: An autoradiographic study of the pontine reticular formation in the cat. J. Comp. Neurol. 175: 37-78.

Graybiel, A. M., and E. A. Hartwieg (1974) Some afferent connections of the oculomotor complex in the cat: An experimental study with tracer techniques. Brain. Res. 81: 543-551.

Gresty, M., and R. Baker (1976) Neurons with visual receptive field, eye movement and neck displacement sensitivity within and around the nucleus prepositus hypoglossi in the alert cat. Exp. Brain Res. 24 $429-433$.

Highstein, S. M. (1971) Organization of the inhibitory and excitatory vestibulo-ocular reflex pathways to the third and fourth nuclei in rabbit. Brain Res. 32: 218-224.

Highstein, S. M. (1973a) The organization of the vestibulo-oculomotor 
and trochlear reflex pathways in the rabbit. Exp. Brain Res. 17:285300.

Highstein, S. M. (1973b) Synaptic linkage in the vestibulo-ocular and cerebello-vestibular pathways to the VIth nucleus in the rabbit. Exp. Brain Res. 17: 301-314.

Highstein, S. M., and R. Baker (1978) Excitatory synaptic termination of abducens internuclear neurons on medial rectus motoneurons: Relationship to syndrome of internuclear ophthalmoplegia. J. Neurophysiol. 41: 1647-1661.

Highstein, S. M., and M. Ito (1971) Differential localization within the vestibular nuclear complex of the inhibitory and excitatory cells innervating IIIrd nucleus oculomotor neurons in rabbit. Brain Res. 29: 358-362.

Highstein, S. M., M. Ito, and T. Tsuchiya (1971) Synaptic linkage in the vestibulo-ocular reflex pathway of rabbit. Exp. Brain Res. 13: 306-326.

Highstein, S. M., K. Maekawa, A. Steinacker, and B. Cohen (1976) Synaptic input from the pontine reticular nuclei to abducens motoneurons and internuclear neurons in the cat. Brain Res. 112: 162167.

Highstein, S. M., A. Karabelas, R. Baker, and R. A. McCrea (1982) Comparison of the morphology of physiologically identified abducens motor and internuclear neurons in the cat: A light microscopic study employing the intracellular injection of horseradish peroxidase. $J$. Comp. Neurol. 208: 369-381.

Highstein, S. M., J. M. Goldherg, A. K. Moschovakis, and C. Fernandez. (1987) Inputs from regularly and irregularly discharging vestibular nerve afferents to secondary neurons in the vestibular nuclei of the squirrel monkey. II. Correlation with output pathways of secondary neurons. J. Neurophysiol. 58: 719-738.

Hikosaka, O., and Y. Igusa (1980) Axonal projection of prepositus hypoglossi and reticular neurons in the brainstem of the cat. Exp. Brain Res. 39: 441-451.

Hikosaka, O., and T. Kawakami (1977) Inhibitory reticular neurons related to the quick phase of vestibular nystagmus-Their location and projection. Exp. Brain Res. 27: 377-396.

Hikosaka, O., M. Maeda, S. Nakao, H. Shimazu, and Y. Shinoda (1977) Presynaptic impulses in the abducens nucleus and their relation to postsynaptic potentials in motoneurons during vestibular nystagmus. Exp. Brain Res. 27: 355-376.

Hikosaka, O., Y. Igusa, S. Nakao, and H. Shimazu (1978) Direct inhibitory synaptic linkage of pontomedullary reticular burst neurons with abducens motoneurons in the cat. Exp. Brain Res. 33: 337-352.

Hirai, N., and Y. Uchino (1984) Superior vestibular nucleus neurones related to the excitatory vestibulo-ocular reflex of anterior canal origin and their ascending course in the cat. Neurosci. Res. 1: 73-79.

Hökfelt, T., and A. Ljungdahl (1975) Uptake mechanisms as a basis for the histochemical identification and tracing of transmitter-specific neuron populations. In The Use of Axonal Transport for Studies of Neuronal Connectivity, W. M. Cowan and M. Cuénod, eds., pp. 249305, Elsevier/North-Holland, Amsterdam.

Igusa, Y., S. Sasaki, and H. Shimazu (1980) Excitatory premotor burst neurons in the cat pontine reticular formation related to the quick phase of vestibular nystagmus. Brain Res. 182: 451-456.

Ishizuka, N., H. Mannen, S. Sasaki, and H. Shimazu (1980) Axonal branches and terminations in the cat abducens nucleus of secondary vestibular neurons in the horizontal canal system. Neurosci. Lett. 16: 143-148.

Isu, N., and J. Yokota (1983) Morphophysiological study on the divergent projection of axon collaterals of medial vestibular nucleus neurons in the cat. Exp. Brain Res. 53: 151-162.

Ito, M., S. M. Highstein, and T. Tsuchiya (1970) The postsynaptic inhibition of rabbit oculomotor neurones by secondary vestibular impulses and its blockage by picrotoxin. Brain Res. 17: 520-523.

Ito, M., N. Nisimaru, and M. Yamamoto (1976a) Pathways for the vestibulo-ocular reflex excitation arising from semicircular canals of rabbits. Exp. Brain Res. 24: 257-271.

Ito, M., N. Nisimaru, and M. Yamamoto (1976b) Postsynaptic inhibition of oculomotor neurons involved in vestibulo-ocular reflexes arising from semicircular canals of rabbits. Exp. Brain Res. 24: 273283.

Kaneko, C. R. S., C. Evinger, and A. F. Fuchs (1981) Role of cat pontine burst neurons in generation of saccadic eye movements. J. Neurophysiol. 46: 387-408.

Kumoi, K., N. Saito, and C. Tanaka (1987) Immunohistochemical localization of $\gamma$-aminobutyric acid- and aspartate-containing neurons in the guinea pig vestibular nuclei. Brain Res. 416: 22-33.

Langer, T., C. R. S. Kaneko, C. A. Scudder, and A. F. Fuchs (1986) Afferents to the abducens nucleus in the monkey and cat. J. Comp. Neurol. 245: 379-400.

Lanoir, J., J. J. Soghomonian, and G. Cadenel (1982) Radioautographic study of ${ }^{3} \mathrm{H}-\mathrm{GABA}$ uptake in the oculomotor nucleus of the cat. Exp. Brain Res. 48: 137-143.

Llinás, R. (1964) Mechanisms of supraspinal actions upon spinal cord activities. Pharmacological studies on reticular inhibition of alpha extensor motoneurons. J. Neurophysiol. 27: 1127-1137.

López--Barneo, J., J. Ribas, and J. M. Delgado-García (1981) Identification of prepositus neurons projecting to the oculomotor nucleus in the alert cat. Brain Res. 214: 174-179.

Lopez-Barneo, J., C. Darlot, A. Berthoz, and R. Baker (1982) Neuronal activity in prepositus nucleus correlated with eye movement in the alert cat. J. Neurophysiol. 47: 329-352.

Maciewič, R. J., and R. F. Spencer (1977) Oculomotor and abducens internuclear pathways in the cat. In Control of Gaze by Brain Stern Neurons, R. Baker and A. Berthoz, eds., pp. 99-108, Elsevier/NorthHolland Biomedical Press, Amsterdam.

Maciewicz, R. J., C. R. S. Kaneko, S. M. Highstein, and R. Baker (1975) Morphophysiological identification of interneurons in the oculomotor nucleus that project to the abducens nucleus in the cat. Brain Res. 96: 60-65.

Maciewic7, R. J., K. Eagen, C. R. S. Kaneko, and S. M. Highstein (1977) Vestibular and medullary brain stem afferents to the abducens nucleus in the cat. Brain Res. 123: 229-240.

Maeda, M., H. Shimazu, and Y. Shinoda (1971) Inhibitory postsynaptic potentials in the abducens motoneurons associated with the quick relaxation phase of vestibular nystagmus. Brain Res. 26: 420424

Maeda, M., H. Shimazu, and Y. Shinoda (1972) Nature of synaptic events in cat abducens motoneurons at slow and quick phase of vestibular nystagmus. J. Neurophysiol. 35: 279-296.

Magnin, M., J. H. Courjon, and J. M. Flandrin (1983) Possible visual pathways to the cat vestibular nuclei involving the nucleus prepositus hypoglossi. Exp. Brain Res. 51: 298-303.

May, P. J., H. Baker, P.-P. Vidal, R. F. Spencer, and R. Baker (1987) Morphology and distribution of serotoninergic and oculomotor internuclear neurons in the cat midbrain. J. Comp. Neurol. 266: 150170 .

McCrea, R. A., and R. Baker (1985) Anatomical connections of the nucleus prepositus of the cat. J. Comp. Neurol. 237: 377-407.

McCrea, R. A., K. Yoshida, A. Berthoz, and R. Baker (1980) Eye movement related activity and morphology of second order vestibular neurons terminating in the cat abducens nucleus. Exp. Brain Res. 40: $468-473$

McCrea, K. A., A. Strassman, and S. M. Highstein (1987a) Anatomical and physiological characteristics of vestibular neurons mediating the vertical vestibulo-ocular reflexes of the squirrel monkey. J. Comp. Neurol, 264: 571-594.

McCrea, R. A., A. Strassman, E. May, and S. M. Highstein (1987b) Anatomical and physiological characteristics of vestibular neurons mediating the horizontal vestibulo-ocular reflex of the squirrel monkey. J. Comp. Neurol. 264: 547-570.

McMasters, R. E., A. H. Weiss, and M. B. Carpenter (1966) Vestibular projections to the nuclei of the extraocular muscles. Degeneration resulting from discrete partial lesions of the vestibular nuclei in the monkey. Am. J. Anat. 118: 163-194.

Mesulam, M.-M. (1978) Tetramethyl benzidine for horseradish peroxidase neurohistochemistry: A non-carcinogenic blue reaction product with superior sensitivity for visualizing neural afferents and efferents. J. Histochem. Cytochem. 26: 106-117.

Mitsacos, A., H. Reisine, and S. M. Highstein (1983) The superior vestibular nucleus: An intracellular HRP study in the cat. I. Vestibuloocular neurons. J. Comp. Neurol. 215: 78-91.

Miyazaki, S. (1985) Location of motoneurons in the oculomotor nucleus and the course of their axons in the oculomotor nerve. Brain Res. 348: 57-63.

Mize, R. R., R. F. Spencer, and P. Sterling (1981) Neurons and glia in cat superior colliculus accumulate $\left[{ }^{3} \mathrm{H}\right]$ gamma-aminobutyric acid (GABA). J. Comp. Neurol. 202: 385-396.

Nakao, S., S. Sasaki, R. H. Schor, and H. Shimazu (1982) Functional organization of premotor neurons in the cat medial vestibular nucleus 
related to slow and fast phases of nystagmus. Exp. Brain Res. 45: 371-385.

Nomura, I., E. Senba, T. Kubo, T. Shiraishi, T. Matsunaga, M. Tohyama, Y.Shiotani, and .I.-Y.Wu (1984) Neuropeptides and $\gamma$-aminobutyric acid in the vestibular nuclei of the rat: An immunohistochemical analysis. I. Distribution. Brain Res. 311: 109-118.

Obata, K., and S. M. Highstein (1970) Blocking by picrotoxin of both vestibular inhibition and GABA action on rabbit oculomotor neurones. Brain Res. 18: 538-541.

Ohgaki, T., I. S. Curthoys, and C. H. Markham (1988) Morphology of physiologically identified second-order vestibular neurons in cat, with intracellularly injected HRP. J. Comp. Neurol. 276: 387-411.

Peterson, B. W., N. G. Pitts, K. Fukushima, and R. Mackel (1978) Reticulospinal excitation and inhibition of neck motoneurons. Exp. Brain Res. 32: 471-489.

Peyret, D., G. Campistron, M. Geffard, and J.-M. Aran (1987) Glycine immunoreactivity in the brainstem auditory and vestibular nuclei of the guinea pig. Acta Otolaryngol. (Stockh.) 104: 71-76.

Porter, J. D., B. L. Guthrie, and D. L. Sparks (1983) Innervation of monkey extraocular muscles: Localization of sensory and motor neurons by retrograde transport of horseradish peroxidase. J. Comp. Neurol. 218: 208-219.

Precht, W., and R. Baker (1972) Synaptic organization of the vestibulotrochlear pathway. Exp. Brain Res. 14: 158-184.

Precht, W., J. Grippo, and A. Richter (1967) Effects of horizontal angular acceleration on neurons in the abducens nucleus. Brain Res. 5: 527-531.

Precht, W., R. Baker, and Y. Okada (1973a) Evidence for GABA as the synaptic transmitter of the inhibitory vestibulo-ocular pathway. Exp. Brain Res. 18: 415-428.

Precht, W., P. C. Schwindt, and R. Baker (1973b) Removal of vestibular commissural inhibition by antagonists of GABA and glycine. Brain Res. 62: 222-226.

Reisine, H., and S. M. Highstein (1979) The ascending tract of Deiters' conveys a head velocity signal to medial rectus motoneurons. Brain Res. 170: 172-176.

Reisine, H., A. Strassman, and S. M. Highstein (1981) Eye position and head velocity signals are conveyed to medial rectus motoneurons in the alert cat by the ascending tract of Deiters'. Brain Res. 211: 153-157.

Richter, A., and W. Precht (1968) Inhibition of abducens motoneurons by vestibular nerve stimulation. Brain Res. 11: 701-705.

Roffler-Tarlov, S., and E. Tarlov (1975) Reduction of GABA synthesis following lesions of inhibitory vestibulo-trochlear pathway. Brain Res. 91: 326-330.

Scudder, C. A., A. F. Fuchs, and T. P. Langer (1988) Characteristics and functional identification of saccadic inhibitory burst neurons in the alert monkey. J. Neurophysiol. 59: 1430-1454.

Spencer, R. F., and R. Baker (1983) Morphology and synaptic connections of physiologically-identified second-order vestibular axonal arborizations related to cat oculomotor and trochlear motoneurones. Soc. Neurosci. Abstr. 9: 1088.

Spencer, R. F., and R. Baker (1986) Histochemical localization of acetylcholinesterase in relation to motor neurones and internuclear neurones of the cat abducens nucleus. J. Neurocytol. 15: 137-154.

Spencer, R. F., and J. D. Porter (1981) Innervation and structure of extraocular muscles in the monkey in comparison to those of the cat. J. Comp. Neurol. 198: 649-665.

Spencer, R. F., and P. Sterling (1977) An electron microscope study of motoneurones and interneurones in the cat abducens nucleus identified by retrograde intraaxonal transport of horseradish peroxidase. J. Comp. Neurol. 176: 65-86.

Spencer, R. F., R. Baker, and R. A. McCrea (1980) Localization and morphology of cat retractor bulbi motoneurons. J. Neurophysiol. 43: 754-770.

Steiger, H.-J., and J. A. Büttner-Enncver (1978) Rclationship betwcen motoneurons and internuclear neurons in the abducens nucleus: $A$ double retrograde tracer study in the cat. Brain Res. 148: 181-188.
Steiger, H.-J., and J. A. Büttner-Ennever (1979) Oculomotor nucleus afferents in the monkey demonstrated with horseradish peroxidase. Brain Res. 160: 1-15.

Strassman, A., S. M. Highstein, and R. A. McCrea (1986a) Anatomy and physiology of saccadic burst neurons in the alert squirrel monkey. I. Excitatory burst neurons. J. Comp. Neurol. 249: 337-357.

Strassman, A., S. M. Highstein, and R. A. McCrea (1986b) Anatomy and physiology of saccadic burst neurons in the alert squirrel monkey. II. Inhibitory burst neurons. J. Comp. Neurol. 249: 358-380.

Tarlov, E. (1970) Organization of vestibulo-oculomotor projections in the cat. Brain Res. 20: 159-179.

Triller, A., F. Cluzeaud, F. Pfeiffer, H. Betz, and H. Korn (1985) Distribution of glycine receptors at central synapses: An immunoelectron microscopy study. J. Cell Biol. 101: 683-688.

Triller, A., F. Cluzeaud, and H. Korn (1987) Gamma-aminobutyric acid-containing terminals can be apposed to glycine receptors at central synapses. J. Cell Biol. 104: 947-956.

Uchino, Y., and S. Suzuki (1983) Axon collaterals to the extrancular motoneuron pools of inhibitory vestibuloocular neurons activated from the anterior, posterior and horizontal semicircular canals in the cat. Neurosci. Lett. 37: 129-135.

Uchino, Y., N. Hirai, and S. Watanabe (1978) Vestibulo-ocular reflex from the posterior canal nerve to extraocular motoneurons in the cat. Exp. Brain Res. 32: 377-388.

Uchino, Y., S. Suzuki, T. Miyazawa, and S. Watanabe (1979) Horizontal canal input to cat extraocular motoneurons. Brain Res. 177: $231-240$.

Uchino, Y., N. Hirai, S. Suzuki, and S. Watanabe (1980) Axonal branching in the trochlear and oculomotor nuclei of single vestibular neurons activated from the posterior semicircular canal nerve in the cat. Neurosci. Lett. 18: 283-288.

Uchino, Y., N. Hirai, S. Suzuki, and S. Watanabe (1981) Properties of secondary vestibular neurons fired by stimulation of ampullary nerve of the vertical, anterior or posterior, semicircular canals in the cat. Brain Res. 223: 273-286.

Uchino, Y., N. Hirai, and S. Suzuki (1982) Branching pattern and properties of vertical- and horizontal-related excitatory vestibuloocular neurons in the cat. J. Neurophysiol. 48: 891-903.

Uchino, Y., T. Ichikawa, N. Isu, H. Nakashima, and S. Watanabe (1986) The commissural inhibition on secondary vestibulo-ocular neurons in the vertical semicircular canal systems in the cat. Neurosci. Lett. 70: 210-216.

van den Pol, A. N., and T. Gorcs (1988) Glycine and glycine receptor immunoreactivity in brain and spinal cord. J. Neurosci. 8: 472-492.

Wenthold, R. J., J. M. Zempel, M. H. Parakkal, K. A. Reeks, and R. A. Altschuler (1986) Immunocytochemical localization of GABA in the cochlear nucleus of the guinea pig. Brain Res. 380: 7-18.

Wenthold, R. J., D. Huie, R. A. Altschuler, and K. A. Reeks (1987) Glycine immunoreactivity localized in the cochlear nucleus and superior olivary nucleus. Neuroscience 22: 897-912.

Wilson, V.J., and M. Maeda (1974) Connections between semicircular canals and neck motoneurons in the cat. J. Neurophysiol. 37: 346357.

Wilson, V. J., R. R. Gacek, M. Maeda, and Y. Uchino (1977) Saccular and utricular input to cat neck motoneurons. J. Neurophysiol. 40: 63-73.

Yamamoto, M., I. Shimoyama, and S. M. Highstein (1978) Vestibular nucleus neurons relaying excitation from the anterior canal to the oculomotor nucleus. Brain Res. 148: 31-42.

Yoshida, K., R. McCrea, A. Berthoz, and P.-P. Vidal (1982) Morphological and physiological characteristics of inhibitory burst neurons controlling horizontal rapid eye movements in the alert cat. $J$. Neurophysiol. 48: 761-784.

Young, A. B., and R. L. Macdonald (1983) Glycine as a spinal cord neurotransmitter. In Handbook of the Spinal Cord, Vol. 1, R. A. Davidoff, ed., pp. 1-43, Marcel Decker, New York. 